$1997-11$

\title{
Dynamics of Dense Water Cascades at the Shelf Edge
}

\author{
Shapiro, Georgy
}

http://hdl.handle.net/10026.1/9739

10.1175/1520-0485(1997)027<2381:dodwca>2.0.co;2

Journal of Physical Oceanography

American Meteorological Society

All content in PEARL is protected by copyright law. Author manuscripts are made available in accordance with publisher policies. Please cite only the published version using the details provided on the item record or document. In the absence of an open licence (e.g. Creative Commons), permissions for further reuse of content should be sought from the publisher or author. 


\title{
Dynamics of Dense Water Cascades at the Shelf Edge
}

\author{
G. I. SHAPIRO \\ P.P. Shirshov Institute of Oceanology, Russian Academy of Sciences, Moscow, Russia
}

A. E. HILL

School of Ocean Sciences, University of Wales, Bangor, United Kingdom

(Manuscript received 9 October 1996, in final form 27 March 1997)

\begin{abstract}
Plumes of dense shelf water cascade down continental slopes in many parts of the world's oceans and provide a mechanism for shelf-ocean exchange. In this paper a nonlinear process-orientated theory is developed and

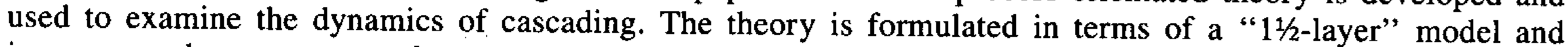
incorporates bottom topography, earth rotation, internal and bottom friction, and entrainment as well as externally imposed pressure gradients. The theory occupies a niche between the stream tube class of model (which considers only bulk properties of a plume) and the full three-dimensional primitive equation approach. The model provides useful insights into the complex interplay between the controlling forces, and it allows one to recover the shape and trajectory of dense plumes as well as the three-dimensional flow field inside the bottom layer. Asymptotic limits are investigated and lead to several basic results. A typical thickness of a fully developed plume is found to be twice the bottom Ekman layer scale, corresponding to reported observations. The relative importance of downslope density-driven cascading and downslope drainage forced by interior currents is assessed. It is found that vertical mixing always assists downslope plume propagation, while an interior current may assist or inhibit cascading. The model is applied to some recent observations at the Hebridean shelf edge west of the British Isles and is used to infer the characteristics of an observed cascade. The model could also be applied to double frontal currents such as the Mediterranean outflow.
\end{abstract}

\section{Introduction}

Overflows of dense water down steep topography in the form of "gravity currents" are a widespread phenomenon in the world's oceans (e.g., Simpson 1982). Examples include the Denmark Strait overflow (Whitehead 1987; Dickson et al. 1990; Jungclaus and Backhaus 1994), the Mediterranean outflow (Price et al. 1993), and inflows over the sills into the Black Sea (Latif et al. 1991) and the Baltic Sea (Lundberg 1983) as well as into numerous smaller-scale fjords. Cascades down the continental slope of dense water formed in shelf seas include those in the Weddell Sea (Gill 1973), the Arctic (Melling and Lewis 1982), Bass Strait and Spencer Gulf, Australia (Tomczac 1985; Lennon et al. 1987), the Adriatic Sea (Zoccolotti and Salusti 1987), and the Celtic Sea (Cooper and Vaux 1949). Much of the present interest in downslope transport stems from the fact that it is a mechanism for ocean-shelf exchange, including for the export of carbon and suspended material from

Corresponding author address: Dr. A. E. Hill, School of Ocean Sciences, University of Wales, Bangor, Marine Science Laboratories, Menai Bridge, Angelsey LL59 5EY United Kingdom. continental shelves to the deep ocean (Huthnance 1995; $\mathrm{Hu}$ and Bai 1995).

Gravity current cascading (Fig. 1) is not, however, the only process that can generate downslope motion at the ocean margin. Other processes (which can occur even in the absence of density gradients) include winddriven downwelling and the bottom Ekman layer transport induced by alongslope currents that impinge on the sea bed (Fig. 1). We call the latter effect "forced Ekman drainage" because it allows water to leak away perpendicular to the principal current direction. For mesoscale processes like cascading and forced drainage, friction is important because it breaks the constraint of potential vorticity conservation, which would require all motion to be alongslope (parallel to isobaths). Time dependence, nonlinearity, and lateral mixing in the momentum balance can also permit the geostrophic constraint to be broken, but these effects shall be omitted in our subsequent analysis leaving friction as the sole means to permit cross-isobath motions.

Hitherto the effort to model dense cascades has made considerable use of the "streamtube" approach described by Smith (1975) and developed by others, notably Killworth (1977) and Price et al. (1993). Streamtube models consider only section-averaged properties of a plume but provide reasonable first-order estimates 


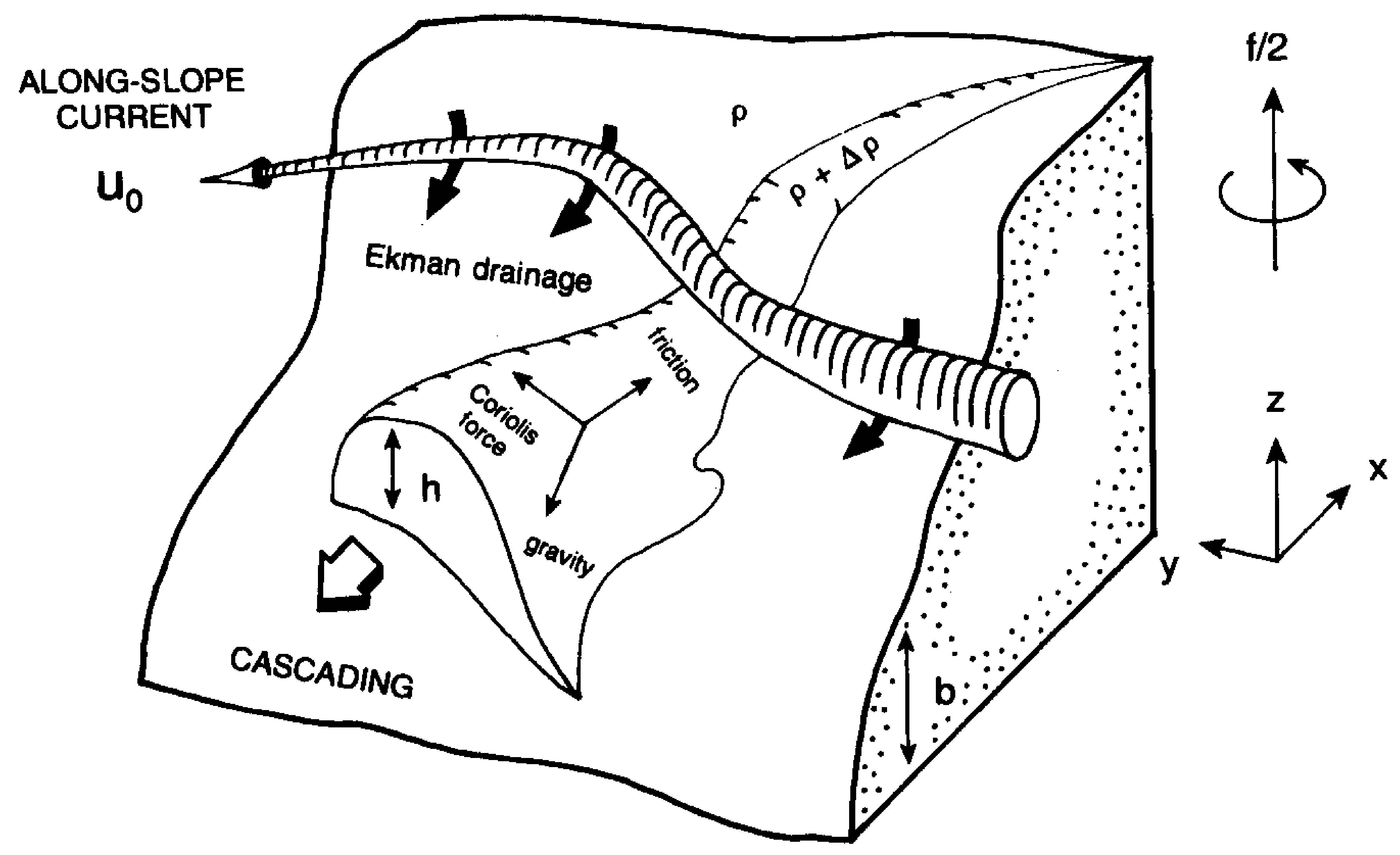

SHELF EDGE CASCADING

FIG. 1. Schematic of cascading and current-forced Ekman drainage on a continental slope.

of plume trajectories. However, they tell us nothing about the internal dynamics of plumes and do not, for example, independently predict the plume thickness without specification of how plume width varies (e.g., Price and Baringer 1994). An attempt to overcome some of these limitations has been made in recent years by use of numerical simulations of the bottom boundary layer using two-layer (Jungclaus and Backhaus 1994) and multilayer (Ezer and Weatherly 1990) primitive equation models. However, in order to gain insight into the underlying physics, there is much to be learned from simpler classes of model that occupy the niche between streamtube and primitive equation models.

Some of the individual ingredients of the cascade problem are contained within the set of simple layered models developed by Shapiro (1982), Nof (1983), Rhines (1989), Speer et al. (1993), Zhmur and Nazarenko (1994), Shapiro and Zatsepin (1996), and others. None of the above models, however, meet all the main requirements for adequate representation of the mesoscale dynamics of cascading at the shelf break. The model by Shapiro (1982) was developed originally for the planetary boundary layer in the atmosphere and allows simulation of the dynamics of three-dimensional features like fronts and lenses but is restricted by the horizontal flat bottom. Nof's (1983) model is based on volume integrated equations and does not include friction. The models developed by Rhines (1989) and Speer et al. (1993) are focused on large-scale effects and assume that friction is weak. The model by Shapiro and Zatsepin (1996) was developed only for an axisymmetric conical bottom topography.

The purpose of this paper is to present a theory that synthesizes most of the main physical elements relevant of the descent of dense cascades over a shelf break and their interactions with overlying interior flows (e.g., bar- otropic and/or baroclinic slope currents). We focus on regions where the level of turbulence and frictional parameters are controlled by "external" driving forces like tides or alongslope currents and develop a differential

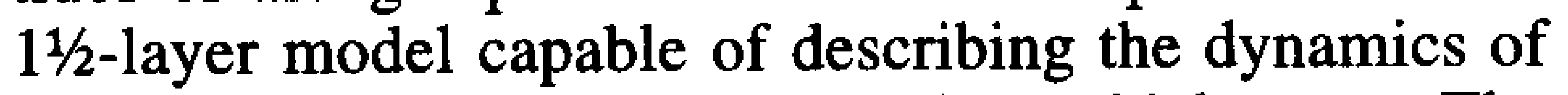
cascading for a range of bottom layer thicknesses. The model is not constrained to two-dimensional or uniform bottom topography and thus, in general, could permit the study of gravity current dynamics in shelf break areas, over banks, and in canyons although, in our later applications, we restrict attention largely to two-dimensional cases.

Particular attention is paid to the situation where the thickness of the bottom layer is of the order of the Ekman depth. A key feature of the model is its ability to predict the thickness of the bottom layer and the location of the plume edge. The important limitation is that the ambient fluid above the bottom dense layer is treated as homogeneous. Since the stratification in the ambient fluid is not specified, the model cannot, for example, predict the downslope penetration of a plume in relation to when it reaches its neutral density level. In spite of this, the principal value of the model is that it allows us to assess the complex interplay of forces that affect the internal dynamics of dense plumes. The simple model structure also results in an efficient numerical code, which is helpful in describing the details of the plume evolution. Moreover, the model is amenable to analytical solution in some special cases, which provides estimates of the main parameters of cascading such as downslope plume speed and bottom layer thickness.

\section{Model description}

Consider a nonlinear three-dimensional mesoscale plume with horizontal scales exceeding the full depth 
of the fluid and with a time-evolution scale exceeding the inertial period. The horizontal scale allows us to employ the hydrostatic approximation for pressure anomalies. We assume also that both along- and acrossslope local accelerations can be disregarded in comparison with the Coriolis force in the momentum balance.

A homogeneous bottom layer of dense fluid is overlain by a deep upper layer. Since we concentrate on the dynamics of the bottom layer and on topographic effects, we use the 11/2-layer approximation (Shapiro 1982; Nof 1983; Rhines 1989), which means that the barotropic circulation (or the velocity distribution in the inviscid core of the upper layer) is prescribed and is used to force the model. The model describes the variable thickness of the bottom layer as well as the current velocities in the bottom layer and in a frictional sublayer of the upper layer near the density interface. The bottom topography is arbitrary except for the restriction that the bottom slope is much smaller than unity, a condition that is almost always satisfied in the ocean, even over the continental slope where gradients are typically of the order of $10^{-1}$ to $10^{-2}$.

The heights above a horizontal datum line of the interface and the seabed are respectively $\xi(x, y, t)$ and $b(x$, $y)$, while $h(x, y, t)=\xi(x, y, t)-b(x, y)$ is the thickness of the bottom layer (Fig. 1). Due to the usually moderate horizontal scale of cascading, an $f$-plane approximation is assumed, although beta-plane or full spherical geometry treatments are possible. The steady, linearized momentum equations in the lower and upper layers are, respectively,

$$
\begin{aligned}
f \mathbf{k} \times \mathbf{u}_{L} & =-\frac{1}{\rho} \nabla p-g^{\prime} \nabla \xi+K \frac{\partial^{2} \mathbf{u}_{L}}{\partial z^{2}} \\
f \mathbf{k} \times \mathbf{u}_{U} & =-\frac{1}{\rho} \nabla p+K \frac{\partial^{2} \mathbf{u}_{U}}{\partial z^{2}},
\end{aligned}
$$

subject to the boundary conditions

$$
\begin{aligned}
& \mathbf{u}_{L}=w_{L}=0 \quad \text { at } z=b(x, y) \\
& \mathbf{u}_{L}=\mathbf{u}_{U}, \quad w_{L}=w_{U}, \quad \partial \mathbf{u}_{L} / \partial z=\partial \mathbf{u}_{U} / \partial z \\
& \text { at } z=\xi(x, y, z, t) \\
& \partial \mathbf{u}_{U} / \partial z=0 \quad \text { as } z \rightarrow \infty \text {. }
\end{aligned}
$$

Here subscripts $L, U$ indicate upper and lower layers respectively, $\boldsymbol{\nabla}=(\partial / \partial x, \partial / \partial y)$ is the two-dimensional gradient operator, $\mathbf{u}(x, y, z, t)=(u, v)$ is the horizontal velocity vector, and $w$ is the vertical velocity component. Since we are considering mesoscale dynamics, velocities are assumed to be the average over a tidal cycle. The pressure in the upper layer is $p$, the upward directed unit vector is $\mathbf{k}$, and $f$ is the Coriolis parameter. The density of the bottom layer is $\rho$ and the reduced gravitational acceleration is $g^{\prime}=g \Delta \rho / \rho$, where $\Delta \rho$ is the density difference between layers.

The momentum equations themselves are steady and linear, so the time dependence and nonlinearity of the problem is introduced later when these are combined with the mass conservation equation below. Physically, the friction terms introduce departures from geostrophy bringing about flow convergence/divergence within the bottom layer and near the density interface, which in turn causes the bottom layer thickness to evolve with time. The formal scale analysis, which explains when this form of momentum equation can be used in the nonlinear prognostic problem, is discussed by Shapiro (1987) and is not repeated here. The continuity equation is the same in both layers;

$$
\frac{\partial u}{\partial x}+\frac{\partial v}{\partial y}+\frac{\partial w}{\partial z}=0
$$

where the subscripts $L, U$ have been dropped. Equation (6) can be integrated vertically over the lower layer from the bottom to the density interface using the well-known nonlinear kinematic boundary condition to give the mass conservation equation

$$
\frac{\partial h}{\partial t}+\boldsymbol{\nabla} \cdot\left(\int_{b}^{\xi} \mathbf{u}_{L} d z\right)=w_{e} .
$$

The entrainment velocity of fluid from the upper to the lower layer is $w_{e}$. The approach imposes no restriction on $h$, which can range from zero to many Ekman depths.

Equations (1)-(2) and the boundary conditions are first expressed in terms of the complex velocity in the usual way and solved subject to the prescribed forcing, boundary, and matching conditions. The resulting expressions for horizontal velocities (in terms of the plume thickness and other parameters) are substituted into the mass conservation equation (7), which, after some manipulation and rearrangement, gives the following governing advection-diffusion-type equation for the interface height that is the mathematical basis of our study:

$$
\begin{aligned}
\frac{\partial h}{\partial t}+ & \left(R_{1} \mathbf{u}_{B}^{S}+R_{2} \mathbf{u}_{0}^{S}+R_{3} \mathbf{u}_{B}+R_{4} \mathbf{u}_{0}\right) \cdot \nabla h \\
= & R_{5} h_{E} \mathbf{k} \cdot\left(\nabla \times \mathbf{u}_{0}\right)+\frac{g^{\prime} h_{E}}{f} \nabla \cdot\left(R_{6} \nabla h\right) \\
& +R_{6} \frac{g^{\prime} h_{E}}{f} \nabla^{2} b+w_{e} .
\end{aligned}
$$

Here $h_{E}=(2 K / f)^{1 / 2}$ is the Ekman depth. The reference velocities that appear in (8) are defined as follows:

$$
\begin{array}{ll}
\mathbf{u}_{B}=\frac{g^{\prime}}{f} \mathbf{k} \times \nabla b & \mathbf{u}_{B}^{s}=-\frac{g^{\prime}}{f} \nabla b \\
\mathbf{u}_{0}=\frac{1}{\rho f} \mathbf{k} \times \nabla p & \mathbf{u}_{0}^{s}=-\frac{1}{\rho f} \nabla p .
\end{array}
$$

These introduce two independent velocity scales into the problem. The first of these, $\left|\mathbf{u}_{0}\right|$, is simply the imposed upper-layer geostrophic speed. The reference velocities $\mathbf{u}_{0}$ and $\mathbf{u}_{0}^{S}$ both have the same magnitude but are 
a

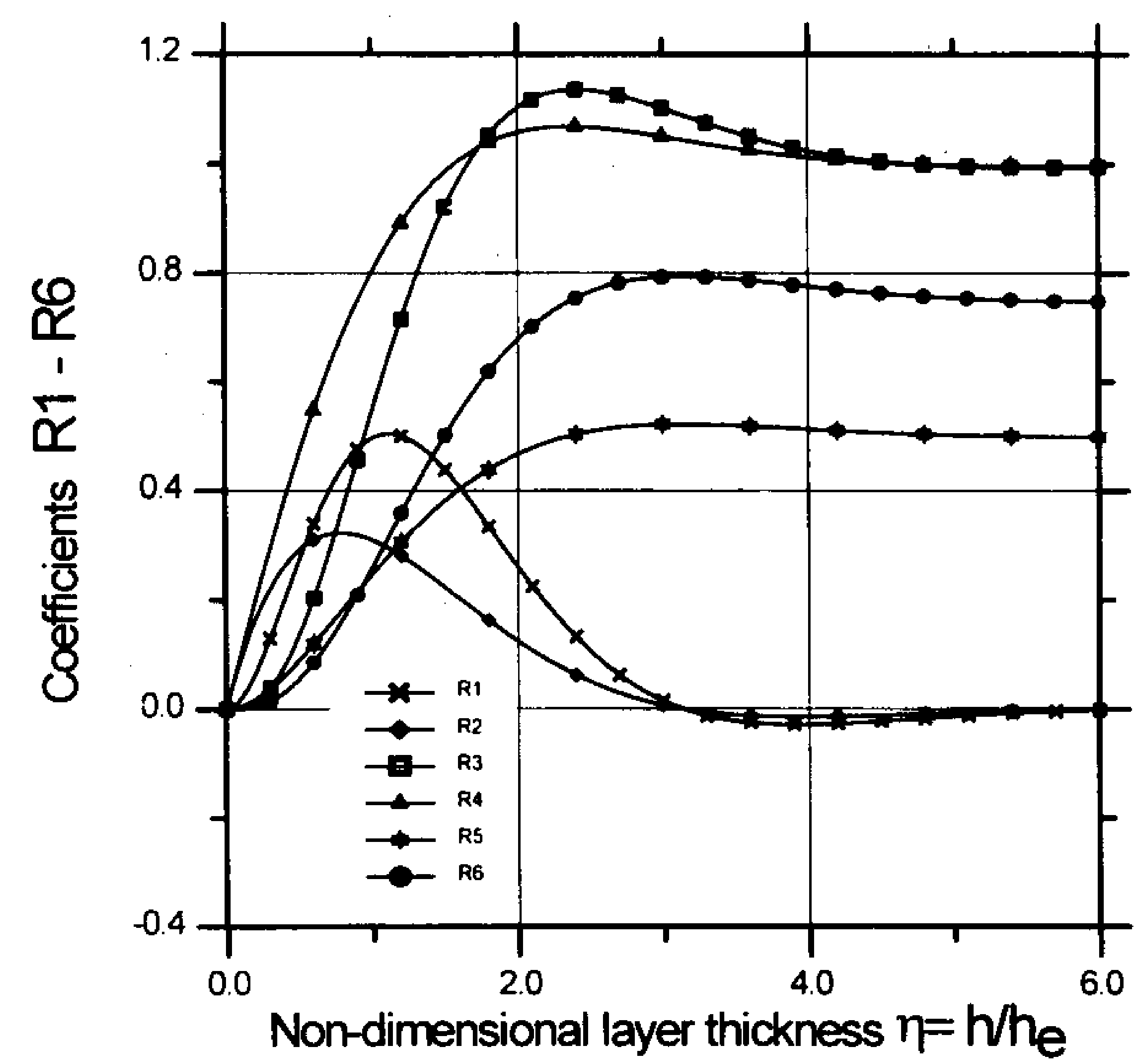

b

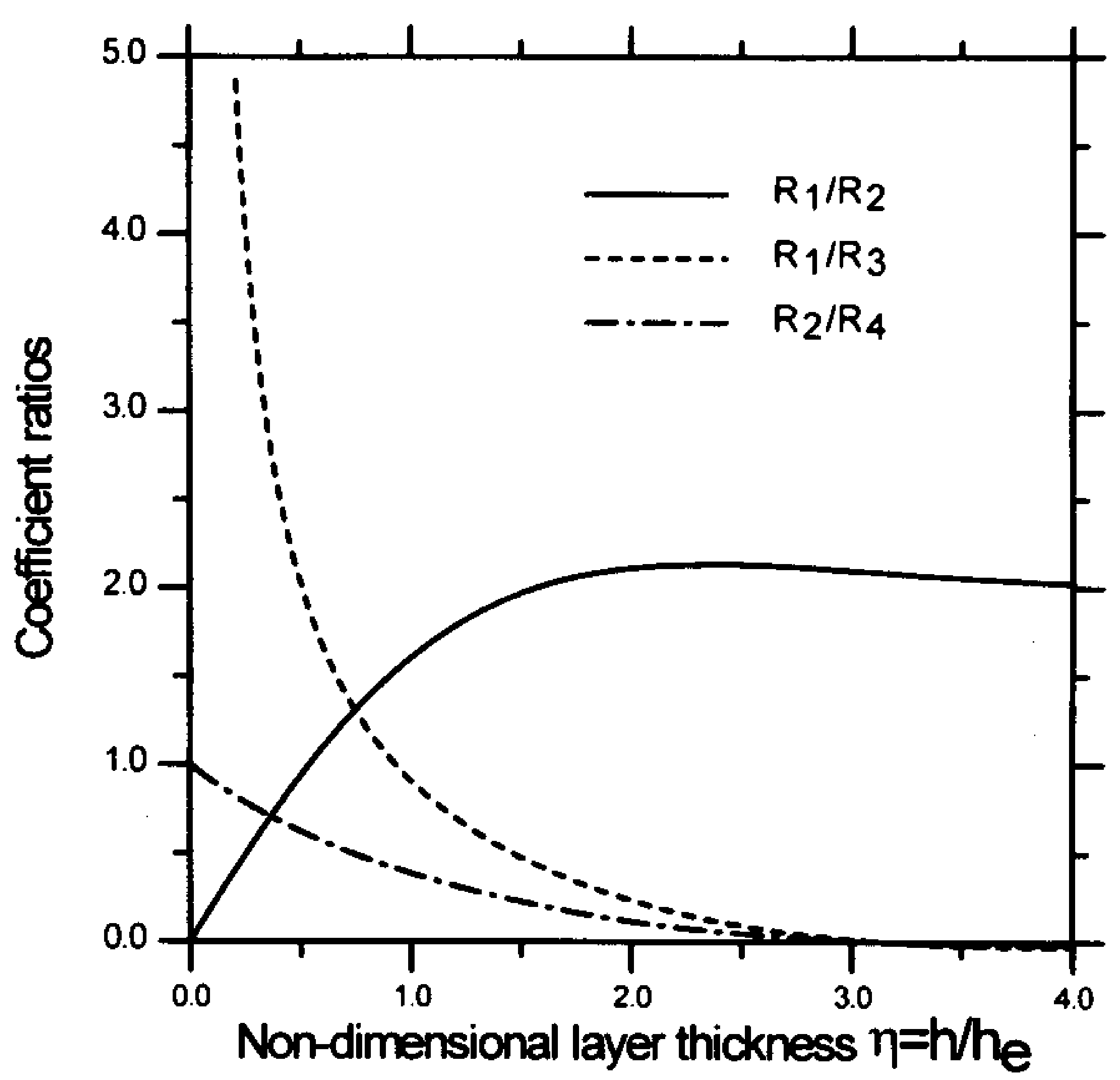

FIG. 2. (a) Coefficients of $R_{1}-R_{6}$ and (b) ratios of the coefficients $R_{2} / R_{4}, R_{1} / R_{3}, R_{1} / R_{2}$, against nondimensional bottom layer thickness.

in the direction of the upper-layer interior flow and at $90^{\circ}$ to the left of it in the Northern Hemisphere, respectively. The second velocity scale, $\left|\mathbf{u}_{B}\right|$, is introduced when there is sloping seabed topography. This scale is the alongslope translation speed of a dense water mass that is subject to a balance between the downslope reduced gravity force $g^{\prime} \sin \theta$ and the upslope component of the Coriolis force $f \cos \theta u_{B}$, where $\tan \theta$ is the bottom slope. This scale $u_{B}=u_{\text {Nof }}=g^{\prime} \tan \theta / f$ was discussed by Nof (1983) in his study of inviscid lens propagation on a uniform bottom slope, and we shall refer to it subsequently as the Nof velocity. The reference velocities $\mathbf{u}_{B}$ and $\mathbf{u}_{B}^{S}$ both have the same magnitude but act alongslope (with the shallow water to the right in the Northern Hemisphere) and downslope respectively.

In Eq. (8), the coefficients $R_{1}$ to $R_{6}$, which have come from the integration of the solution of Eqs. (1), and (2) over the vertical, are functions of the nondimensional bottom layer thickness, $\eta=h / h_{E}$, and are

$$
\begin{aligned}
& R_{1}(\eta)=2 Q(\eta)-Q(2 \eta), \quad R_{2}(\eta)=Q(\eta), \\
& R_{3}(\eta)=2 P(\eta)-P(2 \eta), \quad R_{4}(\eta)=P(\eta), \\
& R_{5}(\eta)=\frac{1}{2}(P(\eta)-Q(\eta)), \\
& R_{6}(\eta)=P(\eta)-Q(\eta)+\frac{1}{4}(Q(2 \eta)-P(2 \eta)), \\
& P(\eta)=1-\cos (\eta) e^{-\eta}, \quad Q(\eta)=\sin (\eta) e^{-\eta} .
\end{aligned}
$$

On account of their $\eta$ dependance, these functions reflect the nonlinearity of plume dynamics. The advection of the interface shape is governed by the four velocities $R_{1} \mathbf{u}_{B}^{S}, R_{2} \mathbf{u}_{0}^{S}, R_{3} \mathbf{u}_{B}, R_{4} \mathbf{u}_{0}$, each of which depend upon the reference velocities and the local layer thickness through the coefficients $R$. The detailed evolution of the bottom layer thickness can thus be expected to be fully threedimensional, and a plume will distort over time as different parts of the plume propagate at different local rates. Indeed, much of the essential physics that determines the behavior of dense bottom-layer plumes can be inferred from the relative magnitudes of the four primary velocity components above. Figure 2 a shows graphs of the coefficients $R_{1}$ to $R_{6}$ versus $\eta$ for the range $0<\eta<6$. As the layer thickness increases in comparison with the Ekman depth, $R_{1}$ and $R_{2}$, which are coefficients of terms representing departure from geostrophy, both tend to zero.

Since Eq. (8) is nonlinear, the four velocities above cannot be interpreted strictly as propagation rates of the plume. However, they do give a broad indication of the magnitude of plume propagation. Given that these provide an estimate of plume propagation rates, we use them below to compare the relative magnitudes of these velocities.

An estimate of the ratio of the advection speed perpendicular to the direction of a forcing interior current (the forced drainage component) to the component of advection in the direction of the forcing current $\left(\mathbf{u}_{0}\right)$ is

$$
\frac{\mid R_{2} \mathbf{u}_{0}^{S \mid}}{\left|R_{4} \mathbf{u}_{0}\right|}=\left(\frac{R_{2}}{R_{4}}\right)
$$

The component of advection in the direction of the interior velocity $\left(R_{4} \mathbf{u}_{0}\right)$ always dominates (Fig. 2), but for progressively thinner bottom layers $(\eta<0.5)$ the difference between advection in the direction of $\mathbf{u}_{0}$ and perpendicular to it is small. As we show later, the typical 
thickness of a well-developed plume is $\eta=1.78$, so the typical value of the ratio $R_{2} / R_{4}$ is 0.16 (Fig. $2 \mathrm{~b}$ ).

In the presence of a bottom slope, an estimate of the ratio of the downslope advection (cascading) to the alongslope density-driven advection is

$$
\frac{\left|R_{1} \mathbf{u}_{B}^{S}\right|}{\left|R_{3} \mathbf{u}_{B}\right|}=\left(\frac{R_{1}}{R_{3}}\right)
$$

For $0<\eta<0.4$ downslope density-driven motions (cascading) prevail over alongslope motion (more than 5 times greater). This represents the fact that in a strongly frictional system the geostrophic constraint is broken and the downslope reduced-gravity component drives the dense water downslope balanced primarily by an upslope friction force. When the bottom layer becomes thicker, however, the importance of friction is reduced in comparison with the effect of rotation, and for $\eta>$ 3 the downslope component of total flux is negligible. For a well-developed plume $(\eta=1.78)$ the typical value of $R_{1} / R_{3}$ is 0.33 (Fig. $2 \mathrm{~b}$ ).

The relative importance of downslope density-driven motion (cascading) and downslope motion due to interior-current-induced bottom Ekman transport (forced drainage) can be assessed by comparing the magnitudes of the second and third terms on the left of (8). Thus, we have

$$
\begin{aligned}
\frac{\text { cascading }}{\text { forced drainage }} & =\frac{\mid R_{1} \mathbf{u}_{B}^{S \mid}}{\left|R_{2} \mathbf{u}_{0}^{S}\right|}=\left(\frac{R_{1}}{R_{2}}\right) \frac{g^{\prime} \tan \theta}{f u_{0}} \\
& =\left(\frac{R_{1}}{R_{2}}\right) \frac{u_{\mathrm{Nof}}}{u_{0}} .
\end{aligned}
$$

Figure $2 \mathrm{~b}$ shows $R_{1} / R_{2}$ for a range of values of nondimensional layer thicknesses. Except for very thin bottom layer thicknesses $(\eta<0.5)$, the ratio $R_{1} / R_{2}$ exceeds unity. For a fully developed bottom layer the above ratio is about 2 (Fig. 2b). Hence, for equivalent forcing of cascading and drainage flows $\left(g^{\prime} \nabla b / f=\nabla p / \rho f\right.$ or equivalently $u_{\text {Nof }}=u_{0}$ ), the cascading response will be twice as great as that due to drainage.

The physical meanings of the terms on the right-hand side of (8) are as follows. The first term represents pumping of the interface because spatial variability (vorticity) in the interior surface-layer flow induces convergent transports in the bottom and interfacial Ekman layers. The second term represents the frictional spreading of the plume in the direction of the baroclinic component of the pressure gradient. Mathematically this appears as a nonlinear diffusion term. The third term arises because of the baroclinic velocity convergence in the Ekman layers due to curvature of the seabed. The last term, of course, represents the effect of entrainment.

\section{Analytical solutions}

In the special case of a flat, horizontal bottom $(b=$ 0 ) and no entrainment $\left(w_{e}=0\right)$, Eq. (8) reduces to the equation developed by Shapiro (1982) to describe the occlusion of tropospheric fronts. When the thickness of the bottom layer greatly exceeds the Ekman scale $(h \gg$ $h_{E}$ ) and, hence, friction is of little importance in the depth integral momentum balance, it follows from (10) that $R_{1} \rightarrow 0, R_{2} \rightarrow 0, R_{3} \rightarrow 1, R_{4} \rightarrow 1, R_{5} \rightarrow 1 / 2, R_{6} \rightarrow$ $3 / 4$. In this case (8), rewritten in terms of interface elevation $\xi=h+b$, reduces in the absence of the barotropic Ekman pumping (the second term on the right) and entrainment (the last term), to the equation for interface evolution obtained by Rhines (1989).

In certain special cases analytical solutions for (8) may be found and some of these are considered below.

\section{a. No bottom slope}

When friction is present, some analytical progress can be made when $\eta \ll 1$ for a flat, horizontal seabed ( $b$ $=0$ ). Suppose that the upper-layer interior current $\mathbf{u}_{0}$ does not vary in time and space, and that entrainment is negligible $\left(w_{e}=0\right)$. To reduce (8) to a scalar equation, the $x$ axis is orientated at $45^{\circ}$ to the left of the direction of $\mathbf{u}_{0}$. In this case (8) reduces to the modified form of the Burger's equation

$$
\begin{aligned}
\frac{\partial \eta}{\partial t} & +\sqrt{2}\left|\mathbf{u}_{0}\right| \eta \frac{\partial \eta}{\partial x} \\
= & \frac{2 g^{\prime} h_{E}}{3 f}\left[\frac{\partial}{\partial x}\left(\eta^{3} \frac{\partial \eta}{\partial x}\right)+\frac{\partial}{\partial y}\left(\eta^{3} \frac{\partial \eta}{\partial y}\right)\right] .
\end{aligned}
$$

The bottom-layer plume is assumed to have constant thickness $\eta_{0}$ far upstream (i.e., $\eta=0$ as $x \rightarrow \infty, \eta=$ $\eta_{0}$ as $x \rightarrow-\infty$ ). In the two-dimensional case (no variation in the $y$ direction), a steady-state solution of the form $\eta=\eta(x-V t)$ exists if there is an upper-layer flow $\left(\left|\mathbf{u}_{0}\right| \neq 0\right)$ and is

$$
\begin{aligned}
& \frac{1}{2}\left(\eta-\eta_{0}\right)^{2}+2 \eta_{0}\left(\eta-\eta_{0}\right)+\eta_{0}^{2} \ln \left|\eta_{0}-\eta\right| \\
& \quad=\frac{3\left|\mathbf{u}_{0}\right| f}{\sqrt{2} g^{\prime} h_{E}}(x-V t) .
\end{aligned}
$$

The speed of the plume edge propagation in the $x \mathrm{di}$ rection for this flat-bottomed forced drainage is

$$
V=\frac{\left|\mathbf{u}_{0}\right|}{\sqrt{2}} \eta_{0}
$$

and the length scale of the interfacial frontal transition from the upstream value to zero is

$$
L_{f}=\frac{\sqrt{2} g^{\prime} h_{E}}{3\left|\mathbf{u}_{0}\right| f} .
$$

If the Rossby radius of deformation based on the Ekman vertical scale is $L_{E}=\left(g^{\prime} h_{E}\right)^{1 / 2} / f$ and the corresponding Rossby number is $\operatorname{Ro}_{E}=1 \mathrm{u}_{0} \mid /\left(f L_{E}\right)$, then $L_{f}=L_{E} / \mathrm{Ro}_{E} \sim$ $L_{E}$ at Rossby numbers of order unity. This means that 
a significant portion of available potential energy is transformed into kinetic energy of the current.

In the absence of an interior forcing current $\left(u_{0}=0\right)$, the problem has a nonstationary similarity solution (e.g., Zeldovich and Kompaneets 1950; Barenblatt 1978), which represents slow diffusive-like spreading of the front according to

$$
x_{\text {front }}=C \eta_{0}^{3 / 2} L_{E} \sqrt{f t} \text { where } C \approx 1 .
$$

\section{b. Uniform bottom slope}

With uniform bottom slope ( $\boldsymbol{\nabla} b=$ const $)$, no friction $\left(h_{E}=0\right)$, no entrainment $\left(w_{e}=0\right)$, and no upper-layer flow $\left(u_{0}=0\right)$, Eq. (8) reduces to the linear advective equation

$$
\frac{\partial \xi}{\partial t}+\mathbf{u}_{B} \cdot \nabla \xi=0
$$

This result alone is interesting because it represents a generalization of Nof's (1983) result concerning the propagation of finite volume dense lenses over a uniform bottom slope. Nof's conclusion was that lenslike eddies (for which interface height goes to zero at their edge) move along isobaths at the same speed regardless of their horizontal size, shape, and maximal depth and that this speed (the Nof speed) is $u_{\mathrm{Nof}}=g^{\prime} \tan \theta / f$ (where the sign of $\tan \theta$ is taken into account in determining the direction of propagation). Equation (19) has the same physical interpretation but it applies under more general conditions that do not require interface intersections with the bed and is thus applicable, for example, to plumes as well as to isolated lenses.

In the case of a two-dimensional frictional plume (no variation alongslope in the $y$ direction), without entrainment $\left(w_{e}=0\right)$ and no interior forcing $\left(u_{0}=0\right)$, Eq. (8) reduces to the nonlinear equation

$$
\frac{\partial h}{\partial t}+u_{B}^{s} R_{1}(\eta) \frac{\partial h}{\partial x}=\frac{g^{\prime} h_{E}}{f} \frac{\partial}{\partial x}\left(R_{6}(\eta) \frac{\partial h}{\partial x}\right),
$$

where $x$ is the downslope direction. If the interface thickness is $\eta_{0}$ far upslope from the interface intersection with the bed, then the boundary conditions on the plume are the same as used previously $(\eta=0$ as $x \rightarrow$ $\infty, \eta=\eta_{0}$ as $x \rightarrow-\infty$ ). Equation (20) has a steadily propagating shock-wave-like solution, $\eta=\eta(x-V t)$, which describes a descending tongue of dense water for which the front of the plume propagates at the constant horizontal speed

$$
V=u_{B}^{s} \frac{R_{6}\left(\eta_{0}\right)}{\eta_{0}}
$$

The solution only exists if $\eta_{0} \leq \eta_{\max }$, and $\eta_{\max }=1.78$ is the value at which the coefficient $R_{1}(\eta)$ equals the value of $R_{6}(\eta) / \eta$. The mathematical reason for this is that the phase plane characteristics of the purely advective (hyperbolic) part of (20) converge only under this condition. This conclusion has the important consequence, referred to previously, that without upper-layer current forcing, the steady stage of dense plume evolution can be obtained only if its thickness does not exceed approximately two Ekman depths. When $\eta_{0}>$ $\eta_{\max }$, there is no analytical solution, but what happens in this case will be discussed in the following section where a numerical treatment is used. For the case of a fully developed plume with maximal upstream thickness, $\eta_{0}=\eta_{\max }$, the downslope cascade speed is

$$
|V|=u_{\mathrm{Nof}} \frac{R_{6}\left(\eta_{\max }\right)}{\eta_{\max }}=0.2 u_{\mathrm{Nof}} .
$$

For shallow bottom-layer depths, $\eta_{0} \ll 1$, (21) yields

$$
V=-\frac{2 g^{\prime} \tan \theta}{3 f} \eta_{0}^{2}
$$

If the interior forcing greatly exceeds the density forcing over topography $\left(u_{0} \gg u_{\text {Nof }}\right)$, the results (16) and (17) for the flat-bottom case can be used to estimate the front propagation speed.

In order to examine the behavior of (8) further it is necessary to turn to a numerical treatment, which is the subject of the following sections.

\section{The numerical model}

In this section, (8) is solved numerically to illustrate the behavior of a dense bottom plume under a range of forcing conditions. We consider first a dense plume on a horizontal flat bottom and then turn to the case of a uniform bottom slope before considering the case of the Hebridean shelf edge west of Britain.

\section{a. The numerical method}

For the numerical solution the following nondimensional variables (denoted by a prime) are introduced into (8): $\left(x^{\prime}, y^{\prime}\right)=(x, y) / L, t^{\prime}=t / T, b^{\prime}=b / h_{E}, \eta=h / h_{E}$, $u^{\prime}=u / U, w_{e}^{\prime}=w_{e} / W, \phi^{\prime}=\phi / \Phi$, where $\phi$ is the geopotential of the upper-layer current, defined by

$$
\boldsymbol{\nabla} \phi=\nabla p / \rho .
$$

The total length of the model domain in the $x$ and $y$ directions is $2 L$ and other scales are as follows:

$$
\begin{aligned}
T & =\frac{f L^{2}}{g^{\prime} h_{E}}, \quad U=\frac{g^{\prime} h_{E}}{f L}, \quad W=\frac{g^{\prime} h_{E}^{2}}{f L^{2}}, \\
\Phi & =g^{\prime} h_{E} .
\end{aligned}
$$

To give a physical idea of the parameters used, the idealized cases presented below were computed with nondimensional parameters corresponding to the following set of dimensional variables: $L=50 \mathrm{~km}, f=$ $10^{-4} \mathrm{~s}^{-1}, g^{\prime}=10^{-3} \mathrm{~m} \mathrm{~s}^{-2}, h_{E}=20 \mathrm{~m}$, which gives $T$ $=1.25 \times 10^{7} \mathrm{~s}, U=0.4 \mathrm{~cm} \mathrm{~s}^{-1}, W=1.6 \times 10^{-4} \mathrm{~cm}$ $\mathrm{s}^{-1}$, and $\Phi=2 \times 10^{2} \mathrm{~cm}^{2} \mathrm{~s}^{-1}$. To ease interpretation, 
results presented below in dimensional form in the figures are discussed in the text in dimensional terms based on the above values.

For the purposes of numerical solution the advective part of (8) was rewritten in divergent form. The numerical scheme is based on the operator splitting method according to which the full spatial operator in (8) is subdivided into several advection and "diffusion" terms. We use the explicit scheme for diffusion with small time steps and modified Lax-Wendroff scheme with larger time steps for the advective terms. The modification of the standard Lax-Wendroff scheme is that for the sake of improved stability, we use averaging over 8 side points at the first substep instead of 4 . Sometimes we used the Godunov scheme (Godunov and Riabenkiy 1973) for improved resolution of shock-wavelike solutions. The problem is solved in a rectangular domain. Unless indicated otherwise, the boundary conditions in the horizontal are $h=0$ at the offshore boundary and $\partial \eta / \partial \mathbf{n}=0$ on all other boundaries.

\section{b. Parameterization of the eddy viscosity $\mathrm{K}$}

Equations (1) and (2) employ the Ekman-style differential form of frictional force with an eddy viscosity coefficient $K$, which does not depend on the plume velocities $u, v$. In this sense the model differs from the streamtube models (Smith 1975; Killworth 1977), where a quadratic bottom drag law is used. When the level of turbulence is controlled primarily by conditions external to the bottom current itself (e.g., tides or alongslope currents, which have velocity $U_{T}$ ), the relation between $K$ and the external forcing is obtained by setting $K U_{T} /$ $h_{E}=C_{d} U_{T}^{2}$, which gives

$$
K=2 \frac{C_{d} u_{*}^{2}}{f}
$$

where $u_{*}=\left(C_{d}\right)^{1 / 2} U_{T}$ is the friction velocity based on the background external forcing velocity outside the frictional wall layer (e.g., the tidal current amplitude). For the widely used value, $C_{d}=2.5 \times 10^{-3}$, for shallow seas (24) coincides with the empirical relation given by Csanady (1976).

\section{c. Parameterization of entrainment}

There are many approaches to the estimation of interfacial entrainment for two-layer models (e.g., Smith 1975; Csanady 1984; Jungclaus and Backhaus 1994). For the present purpose we start with the parameterization used by Csanady (1984);

$$
\frac{w_{e}}{u_{*}}=C_{C} \frac{u_{*}^{2}}{g^{\prime} h}
$$

where $h$ is the thickness of the plume and $C_{C}=0.32$ is an empirical constant. Combining (24) and (25), the entrainment velocity is given by

$$
w_{e}=\frac{C_{C} f^{3} h_{E}^{2}}{8 C_{d}^{3 / 2} g^{\prime}} F\left(\frac{h_{E}}{h}\right) .
$$

When the bottom layer is much thicker than the Ekman layer, the velocity shear used in the determination of $u_{*}$ is calculated over the Ekman depth $h_{E}$; when the bottom layer is thinner than the Ekman layer, the shear is calculated over the depth $h$. Hence $F\left(h_{E} / h\right)=h_{E} / h$ if $h>h_{E}$ and $F\left(h_{E} / h\right)=1$ if $h<h_{E}$. For the purpose of this paper it is not the details of the entrainment parameterization that are crucial but the fact that the bottom layer can thicken during the course of the motion so altering the force balance within the plume.

\section{Numerical model results}

In the following cases ( $a, b, c$, and e) both bottom topography and the initial shape of the plume were taken as two-dimensional without any variation in the $y$ direction. In case d, the bottom topography was two-dimensional, while the plume initially had a three-dimensional shape. However, the full three-dimensional model was applied in each case.

\section{a. Flat, horizontal seabed}

Figure 3 shows the shape of the dense water plume plotted as nondimensional interface height $\eta=h / h_{E}$ versus the nondimensional horizontal distance $x / L$. Successive interface shapes are shown for times corresponding to dimensional values $t=0,5,10$, and 15 days. Dimensional times are calculated using the set of dimensional scales introduced in the previous section. Initially the interface is horizontal for $x / L>0.5$ and has a thickness of five Ekman scales $\left(\eta=h / h_{E}=5\right)$, which tapers to zero between $0<x / L<0.5$.

In the base case, there is no entrainment $\left(w_{e}=0\right)$ and no externally imposed interior current forcing $\left(u_{0}=0\right)$, that is, the upper layer at rest throughout the motion. Figure 3a shows how the density interface spreads slowly under the pressure gradient opposed by earth rotation and friction. Note that the primary flow is geostrophic in the positive $y$ direction and hence into the page. In this case the motion is governed by a reduced form of Eq. (8), which represents a diffusionlike spreading of the interface (where the entrainment term has been set to zero):

$$
\frac{\partial h}{\partial t}=\frac{g^{\prime} h_{E}}{f} \nabla\left(R_{6} \nabla h\right)+w_{e} .
$$

This form of the interface equation is well known and was discussed, for example, by Garrett and Loder (1981). The diffusion effect arises because physically there is a tendency for flow to be down the density gradient (rather than parallel to density contours) within the bottom and interfacial Ekman layers.

Figure $3 \mathrm{~b}$ shows the case where the upper-layer flow 
a

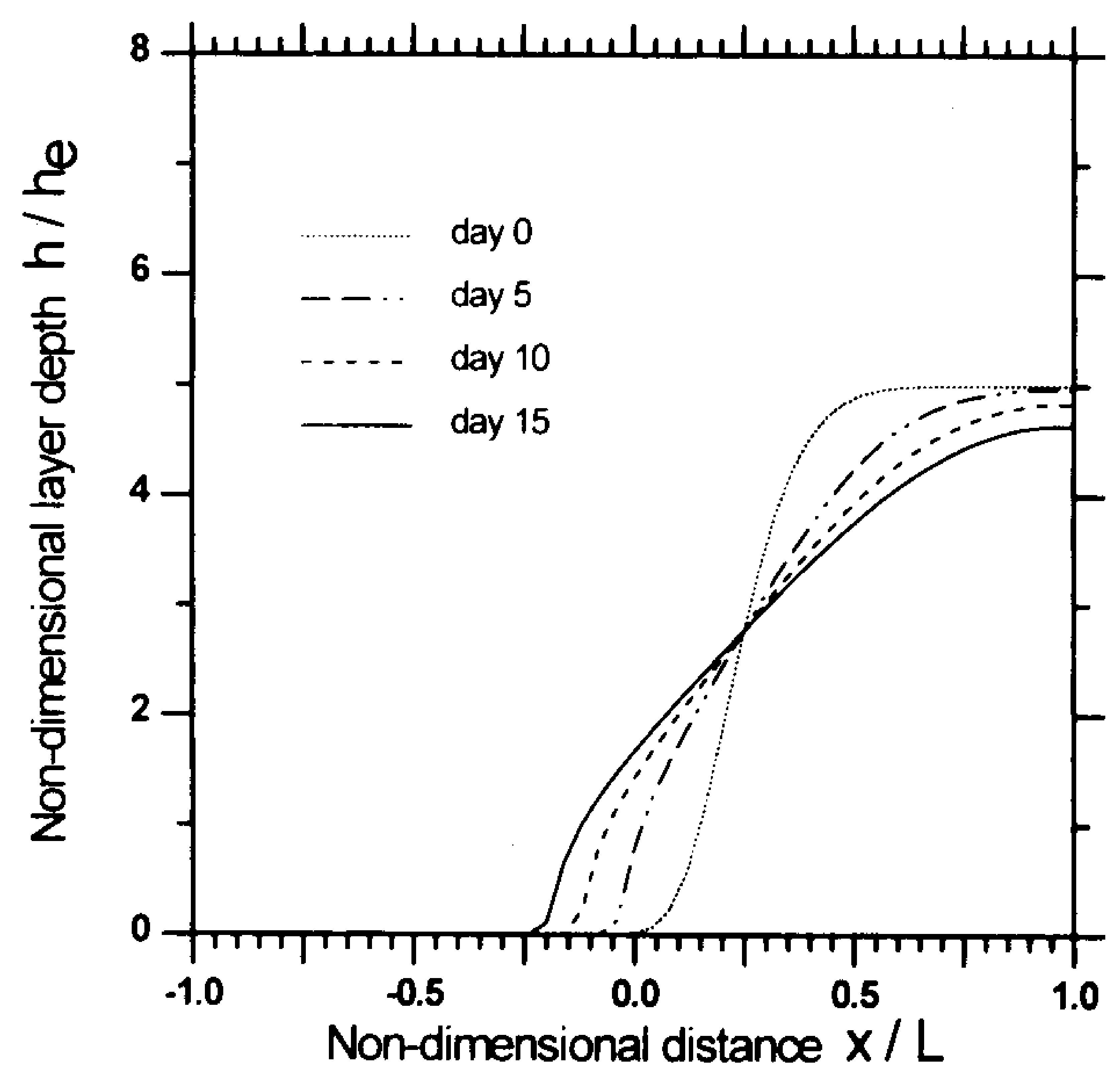

C

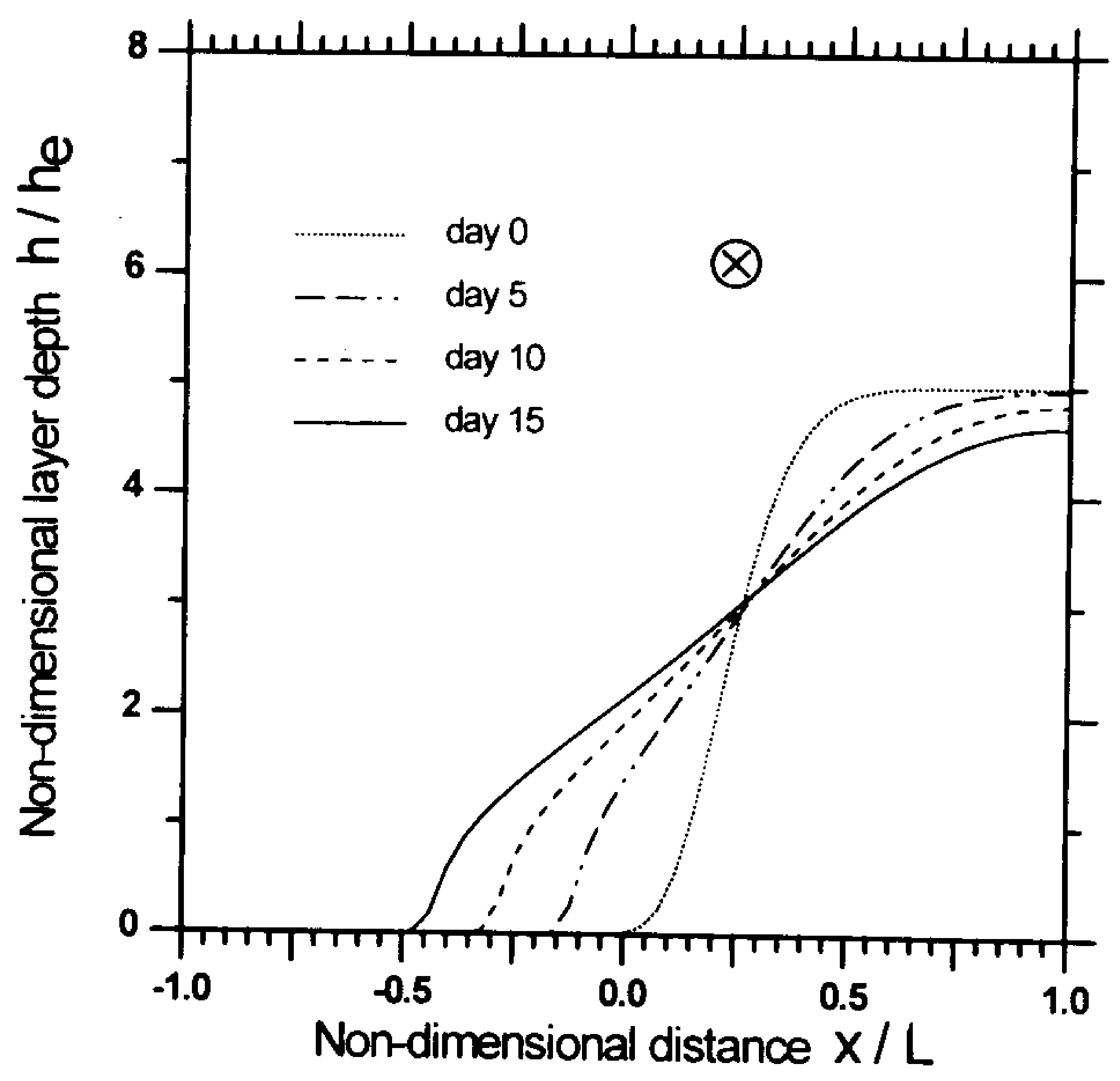

is again zero $\left(u_{0}=0\right)$ but where entrainment is included with $w_{e}=11 \mathrm{~m} \mathrm{~d}^{-1}$. The governing equation is (27). Surprisingly the effect of entrainment is to enhance the rate of propagation of the density interface. The role of entrainment can be explained physically as follows. Only when the density gradient is sufficiently sharp (i.e., the density interface is steep) can the rate of propagation of a plume be large. Without entrainment, the only source of water supply necessary to steepen the interface b

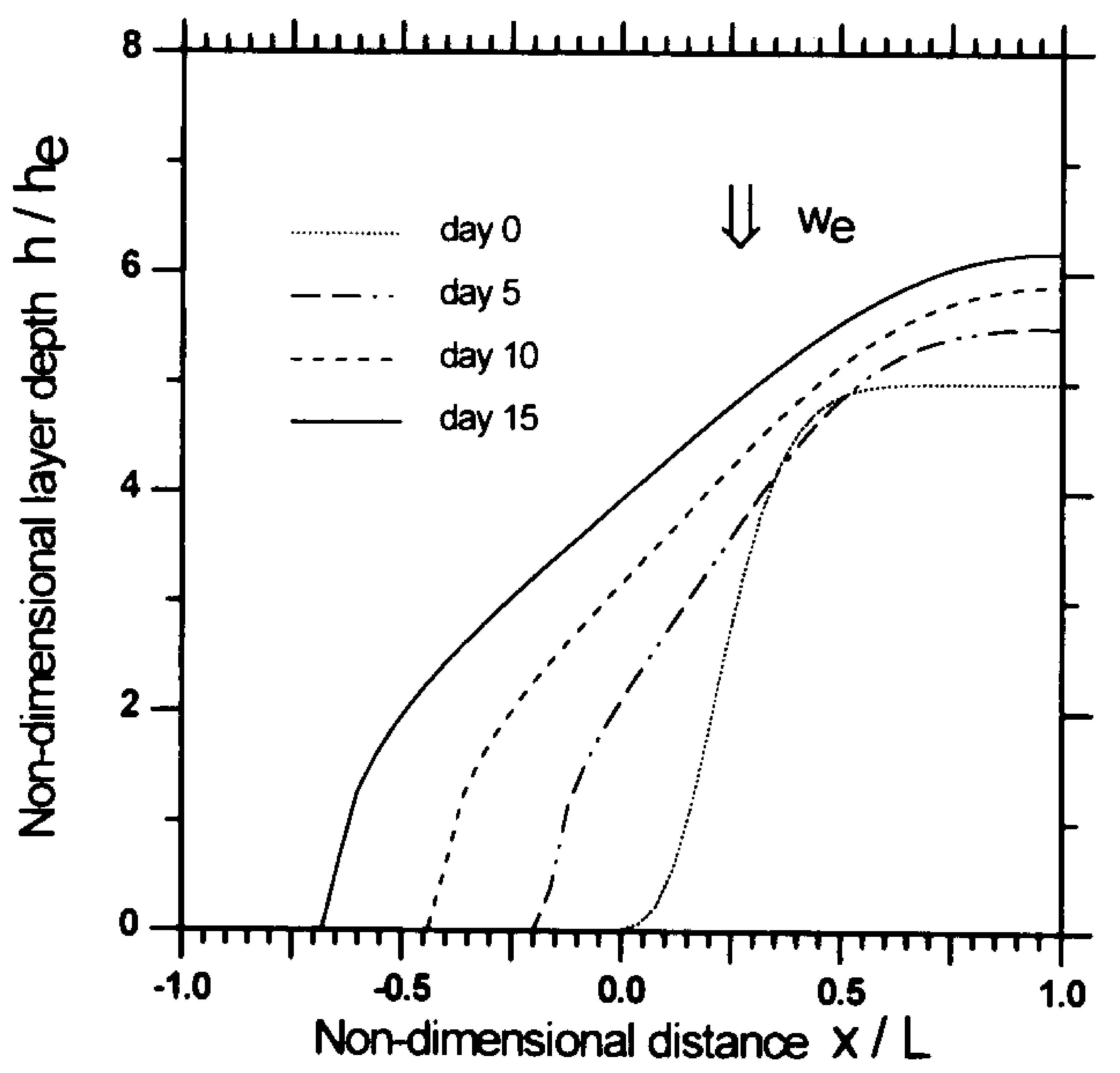

FIG. 3. Evolution of a $2 \mathrm{D}$ plume on a horizontal bottom. The maximum nondimensional upslope interface thickness is $\eta_{m}=5(h$ $=100 \mathrm{~m}$ ). Interface height is shown on sections normal to the plume edge for times $t^{\prime}=0, t^{\prime}=3.4 \times 10^{-2}(5$ days $), t^{\prime}=6.9 \times 10^{-2}$ (10 days), $t^{\prime}=10.4 \times 10^{-2}(15$ days $)$ when (a) $\nabla^{\prime} \phi^{\prime}=0\left(u_{0}=0\right)$, $w_{e}^{\prime}=0$; (b) $\nabla^{\prime} \phi^{\prime}=0\left(u_{0}=0\right), w_{e}^{\prime}=80\left(w_{e}=11 \mathrm{~m} \mathrm{day}^{-1}\right)$; and (c) $\nabla^{\prime} \phi^{\prime}=10\left(u_{0}=0.04 \mathrm{~m} \mathrm{~s}^{-1}\right), w_{e}^{\prime}=0$. The figures in brackets are dimensional values based on the dimensional scales given in the text.

is from the main body of the plume. At the leading edge, however, where the thickness of the bottom layer is small, friction strongly inhibits this supply of water. Entrainment, on the other hand, breaks this constraint by thickening the leading edge, enabling more water to enter from the main body of the plume.

Figure $3 \mathrm{c}$ shows the remaining key influence on interface propagation in the flat-bottomed case. All the initial parameters are kept the same except that entrain- 
ment is removed once more $\left(w_{e}=0\right)$, and, instead, a uniform upper-layer flow (directed into the page) is imposed with $u_{0}=0.04 \mathrm{~m} \mathrm{~s}^{-1}$. The effect is to increase the rate of advance of the bottom front (nearly double the rate in Fig. 3a for this particular parameter choice). In these circumstances, the spread of interface is governed by

$$
\frac{\partial h}{\partial t}+\left(R_{2} \mathbf{u}_{0}^{S}+R_{4} \mathbf{u}_{0}\right) \cdot \nabla h=\frac{g^{\prime} h_{E}}{f} \nabla\left(R_{6} \nabla h\right)
$$

It is the inclusion of second term on the left-hand side that is responsible for the increased speed of propagation perpendicular to the direction of geostrophic flow. Physically this represents the effect of bottom Ekman transport induced by the interior current.

\section{b. Uniform bottom slope}

Figure 4 shows what happens when dense water is released over uniform bottom slope with gradient $4 \times$ $10^{-3}$ (calculated from dimensional variables). The evolution of the plume is shown for times corresponding to the dimensional values $t=0,2,5,7,10$ days. The initial condition is that, far upslope, the layer thickness is five Ekman scales for $x / L>0.5$ and, for $0<x / L<$ 0.5 , the interface height tapers to zero.

Figure 4a shows the base case when there is no upperlayer flow $\left(u_{0}=0\right)$ and no entrainment $\left(w_{c}=0\right)$. The governing equation (dropping the entrainment term on the far right) is then

$\frac{\partial h}{\partial t}+\left(R_{1} \mathbf{u}_{B}^{s}+R_{3} \mathbf{u}_{B}\right) \cdot \nabla h=\frac{g^{\prime} h_{E}}{f} \nabla\left(R_{6} \nabla h\right)+w_{e}$.

As before, propagation of the interface is induced by diffusionlike spreading effect explained previously. Additionally, however, the effect of bottom slope comes into play because the downslope component of the (reduced) gravity force will tend to produce downslope motion. Outside the Ekman layer this force is geostrophically balanced and all motion is parallel to the slope. Within the frictional Ekman layer, part of the downslope gravity force is unopposed by rotation so some downslope motion is possible. It is this part of the motion that is represented by the second term on the left of (29). The alongslope propagation of the density interface is represented by the third term on the left of (29), which is thus not relevant to the motion visible in Fig. 4a.

The effect of the addition of entrainment with a value of $w_{e}=11 \mathrm{~m} \mathrm{~d}^{\prime}$ (while the upper layer flow is still absent, $u_{0}=0$ ) is shown in Fig. 4b. As with the flatbottomed case, the downslope propagation of the density interface is enhanced for the same physical reason as explained above.

Figure $4 \mathrm{c}$ shows the effect of the introduction of a uniform alongslope current (in the positive $y$ direction, directed into the page) with a speed of $u_{0}=0.04 \mathrm{~m} \mathrm{~s}^{-1}$, while entrainment remains zero $\left(w_{e}=0\right)$. The governing equation for interface propagation in these circumstances is

$$
\begin{aligned}
\frac{\partial h}{\partial t} & +\left(R_{1} \mathbf{u}_{B}^{S}+R_{2} \mathbf{u}_{0}^{S}+R_{3} \mathbf{u}_{B}+R_{4} \mathbf{u}_{0}\right) \cdot \nabla h \\
& =\frac{g^{\prime} h_{E}}{f} \nabla\left(R_{6} \nabla h\right) .
\end{aligned}
$$

The effect of the addition of the interior flow is to induce downslope drainage (to the left of the flow) in the bottom Ekman layer. With flow into the page as prescribed, the interior flow induces downslope Ekman transport, which assists the gravity force, and hence downslope propagation is enhanced.

Figure $4 \mathrm{~d}$ shows the effect of reversing the direction of the imposed interior flow [now directed in the negative $y$ direction, out of the page with speed five times that used in Fig. $\left.4 \mathrm{c}\left(0.2 \mathrm{~m} \mathrm{~s}{ }^{1}\right)\right]$. Entrainment remains absent $\left(w_{e}=0\right)$. The effect of barotropic forcing in this case is to arrest or block the downslope propagation of dense fluid (blocked cascading) since the bottom-layer Ekman transport opposes the direction of downslope propagation.

\section{c. Shockwave behavior}

The existence of a stationary shock-wave solution for Eq. (21) was demonstrated analytically for the case of $\eta<\eta_{\max }$. However, the question remains as to what happens if $\eta>\eta_{\max }$ when no analytical solution exists. To examine this question, a model simulation was performed with an initial upper-layer thickness of $5 h_{E}$, bottom slope $2 \times 10^{-2}$, and no entrainment or interior current ( $w_{\mathrm{e}}=0$ and $u_{0}=0$ ). The result is presented in Fig. 5, which shows that even when the initial layer thickness is large, a propagating nose forms that has a thickness of the order of two Ekman depths. Thus regardless of the initial condition, part of the plume will propagate downslope in a shock-wave-like form that satisfies the condition that $\eta<\eta_{\max }$. The result that the thickness of fully developed (shock-wave-like) plumes is about two Ekman depths allows us to account for a well-known observational result (e.g., Armi and D'Asaro 1980) that the mean turbulent Ekman layer height is roughly half the mean bottom mixed layer height. After some time the propagation of the plume becomes stationary with a speed consistent with the analytical solution (22).

\section{d. Three-dimensional plume on a sloping bottom}

The above results show how the plume propagates under various conditions on a uniform slope. As mentioned previously, however, the coefficients $R_{1}$ to $R_{4}$, which determine the propagation rate of the interface, depend themselves on the interface height. Hence the downslope and alongslope velocities vary from place to 
a
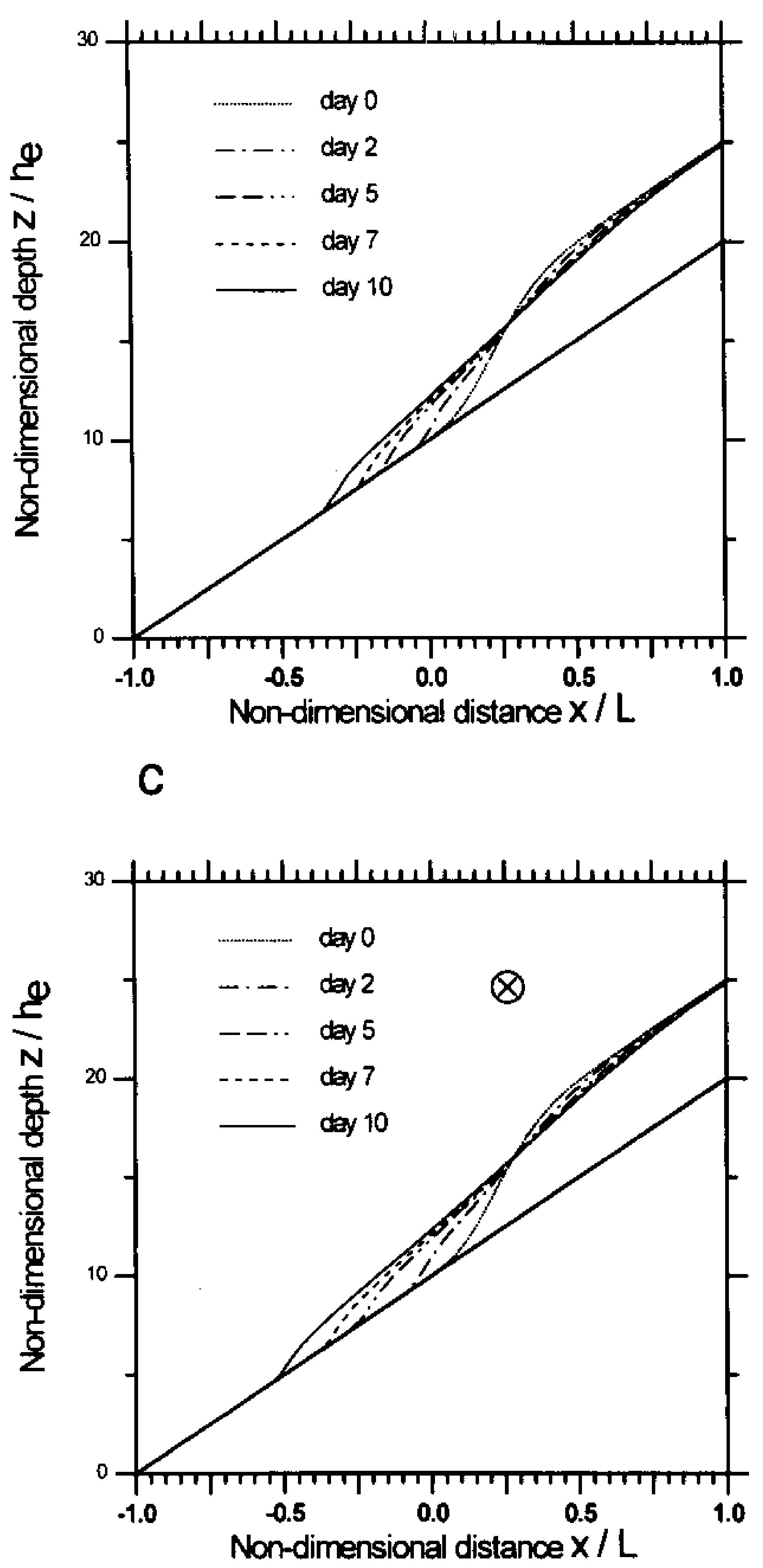

b
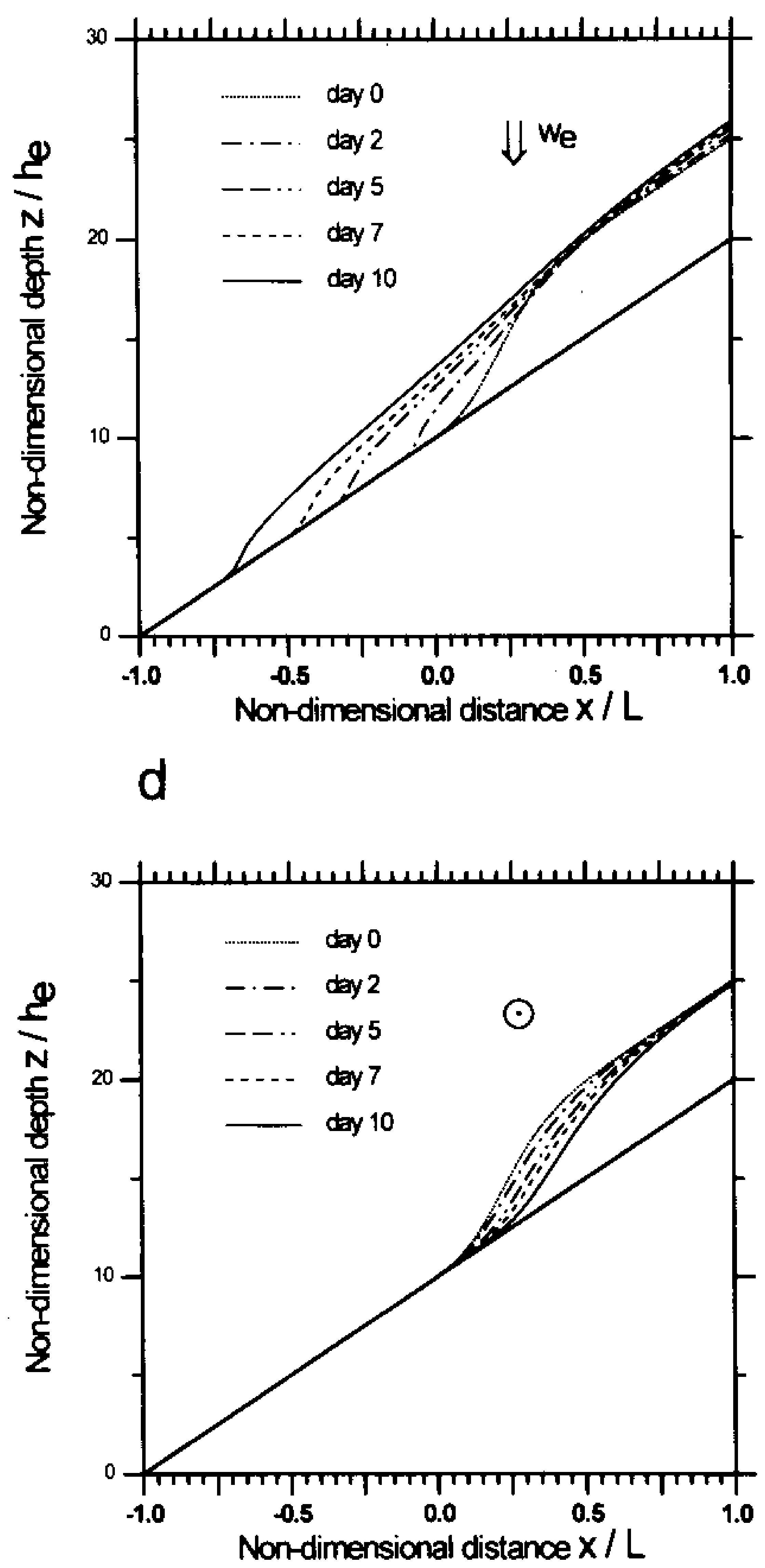

FIG. 4. Evolution of a $2 D$ plume on a slope. In all cases, the nondimensional bottom depth is $\nabla^{\prime \prime} b^{\prime}=10\left(\nabla b=4 \times 10^{-3}\right)$ and the maximum nondimensional upslope interface thickness is $\eta_{m}=5\left(h_{m}=100 \mathrm{~m}\right)$. Interface height is shown on sections normal to the plume edge for times $t^{\prime}=0, t^{\prime}=1.4 \times 10^{-2}(2$ days $), t^{\prime}=3.4 \times 10^{-2}(5$ days $), t^{\prime}=4.8 \times 10^{-2}(7$ days $), t^{\prime}=6.9 \times 10^{-2}(10$ days $)$ when $(\mathrm{a})$ $\nabla^{\prime} \phi^{\prime}=0\left(u_{0}=0\right), w_{e}^{\prime}=0$; (b) $\nabla^{\prime} \phi^{\prime}=0\left(u_{0}=0\right), w_{e}^{\prime}=80\left(w_{\varepsilon}=11 \mathrm{~m} \mathrm{day}^{-1}\right)$; (c) $\nabla^{\prime} \phi^{\prime}=10\left(u_{0}=0.04 \mathrm{~m} \mathrm{~s}^{-1}\right), w_{e}^{\prime}=0 ;(\mathrm{d}) \nabla^{\prime} \phi^{\prime}=$ $50\left(u_{0}=-0.2 \mathrm{~m} \mathrm{~s}^{-1}\right), w_{x}^{\prime}=0$.

place in a plume of nonuniform thickness. To illustrate this behavior, Fig. 6 shows the situation when a plume is released over a uniform bottom slope $\left(4 \times 10^{-3}\right.$, computed from dimensional variables) in the presence of an upper-layer current $u_{0}=0.2 \mathrm{~m} \mathrm{~s}^{-1}$. Contours show the plan view of the nondimensional bottom layer thick- ness in nondimensional space $x / L, y / L$. Initially the plume has a maximum height of $5 h_{E}$ at $y / L=0$ on the right-hand boundary (Fig. 6a). The shape of the interface on this boundary is kept invariant over time to represent a continuous source of dense fluid. The plume is shown again 2.3 days later (Fig. 6b). Over time the 


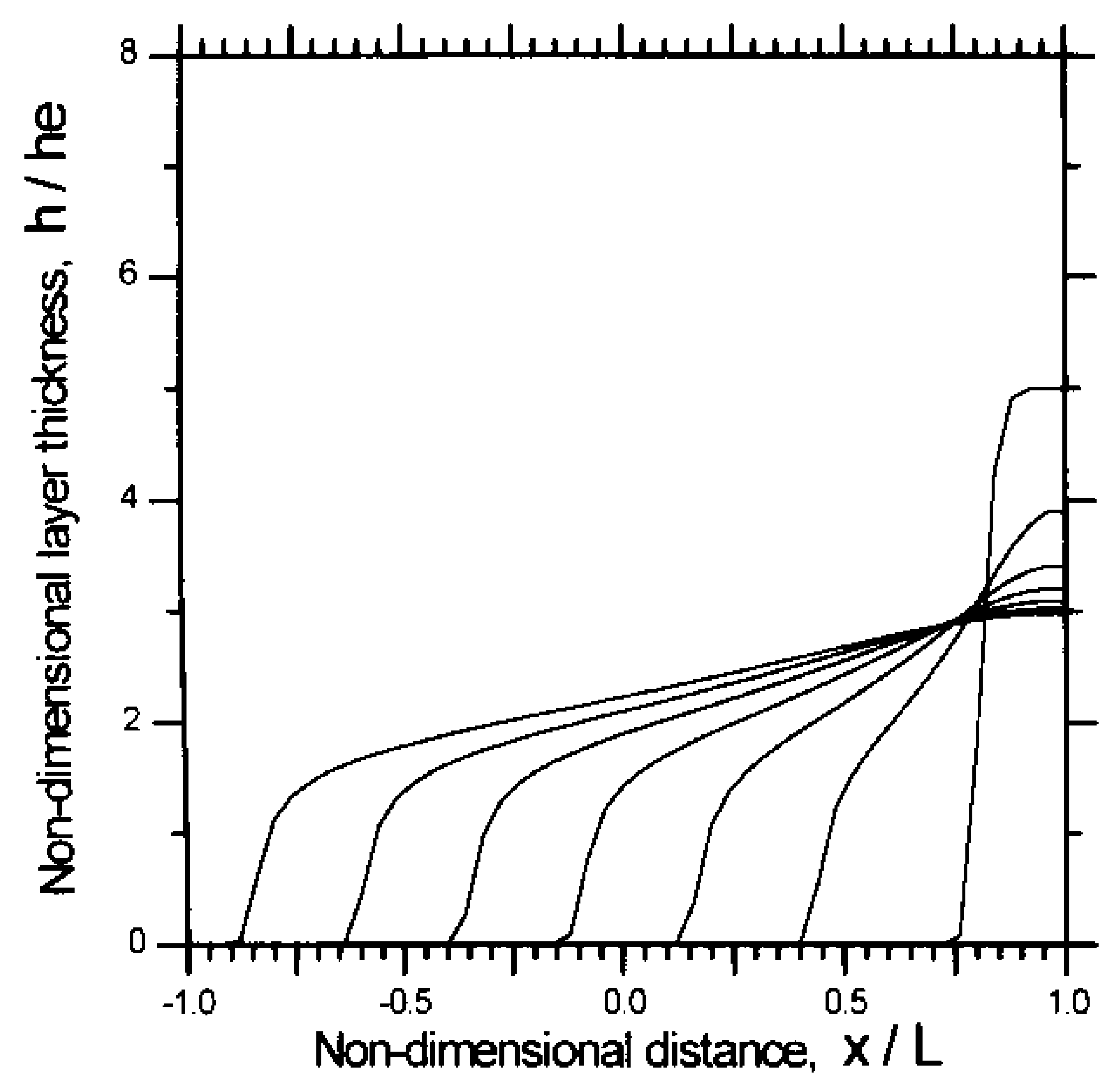

Fig. 5. Shock-wave formation on a sloping bottom. The parameters are $\nabla^{\prime} b^{\prime}=50\left(\nabla b=2 \times 10^{-2}\right)$, nondimensional geopotential gradient $\nabla^{\prime} \phi^{\prime}=0\left(u_{0}=0\right)$, maximum nondimensional layer thickness, $\eta_{m}=$ $5\left(h_{m}=100 \mathrm{~m}\right)$ for times $t^{\prime}=0$ to $t^{\prime}=8.4 \times 10^{-2}(12$ days $)$ with the interface shown at time intervals $\Delta t^{\prime}=1.4 \times 10^{-2}$ ( 2 days). The solution shows the formation and evolution of a nose about two Ekman layers thick that propagates as a stationary shock wave.

dense fluid propagates both downslope under the influence of reduced gravity and friction and is deflected to the right under the influence of rotation. The shape of the dense plume distorts severely over time due to the different propagation speeds within the plume. A semi-

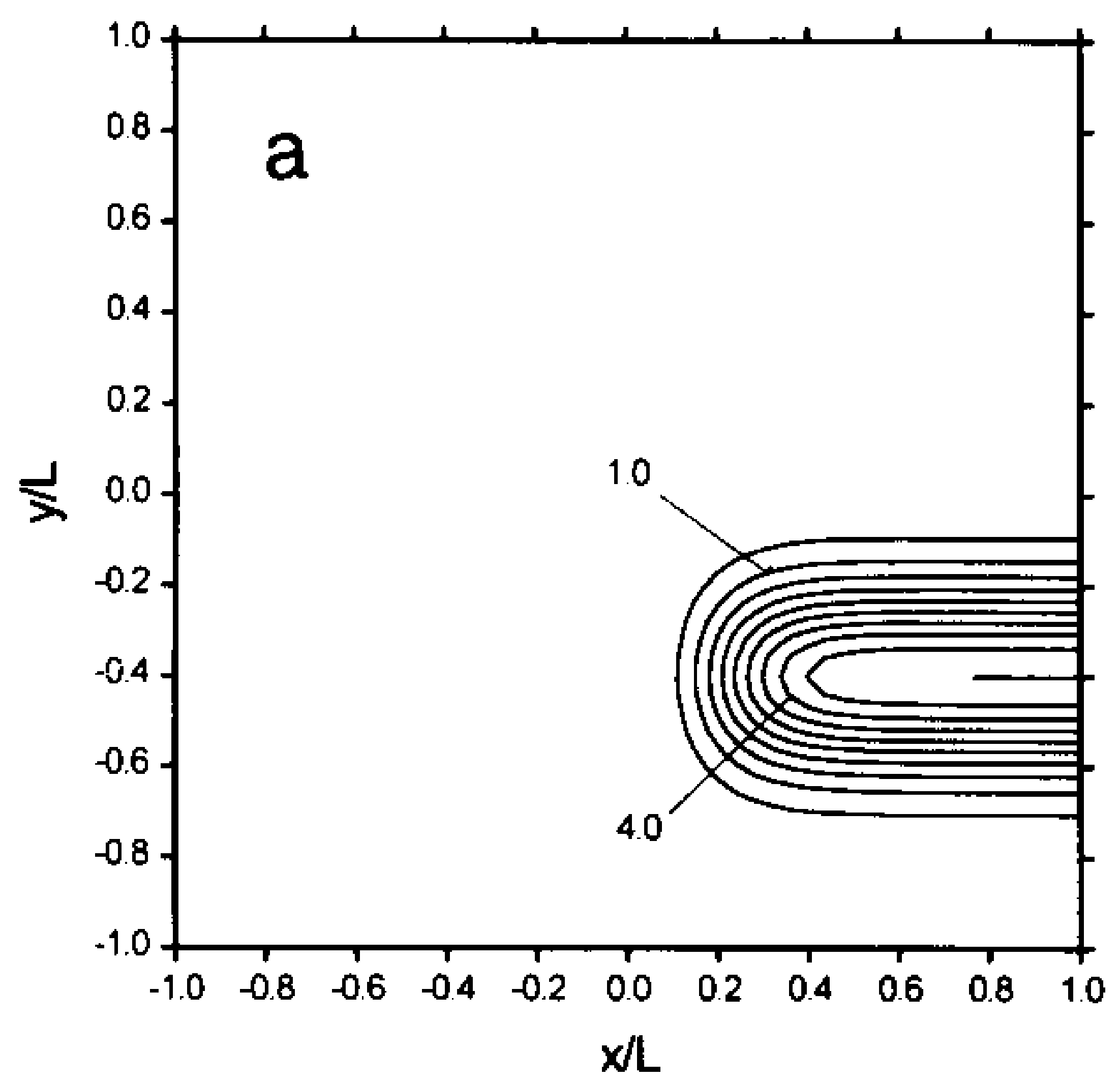

isolated lens is formed at the front of the plume and an abrupt shock-wave-like structure is established at the leading edge. Numerical simulations suggest that small changes in the initial plume shape do not influence the plume behavior significantly.

\section{e. The Hebrides shelf edge}

The possibility that dense winter water cascades might exist at the northwest European shelf edge was first raised by Nansen (1913) and Cooper and Vaux (1949). Some evidence for cascading down the slope of Rockall Bank west of Britain was obtained by Ellett in 1968 (reviewed by Huthnance 1995). Additionally a narrow (order $20-50 \mathrm{~km}$ wide) slope current flows poleward year-round along the upper slope (above $500 \mathrm{~m}$ ) west of the British Isles with characteristic surface speeds of about $0.05-0.3 \mathrm{~m} \mathrm{~s}^{-1}$ (Huthnance 1986).

In February 1996, hydrographic observations were made from RRS Challenger at the shelf edge northwest of Ireland as part of the U.K. LOIS (Land Ocean Interaction Study) Shelf Edge Study. The observations will be reported in detail elsewhere, but Fig. 7a is a cross-slope density section obtained from the vicinity of $55^{\circ} \mathrm{N}, 10^{\circ} \mathrm{W}$, which shows what appears to be a cascade of denser shelf water penetrating downslope to a depth of about $500 \mathrm{~m}$, at the top of the main thermocline. The plume has a characteristic thickness of 50-100 m and other tracers (e.g., nutrients and chlorophyll) support the interpretation that this water mass originates from the continental shelf. The cascade was found only on this particular section, and transects $100 \mathrm{~km}$ alongslope both to the north and south of this section showed

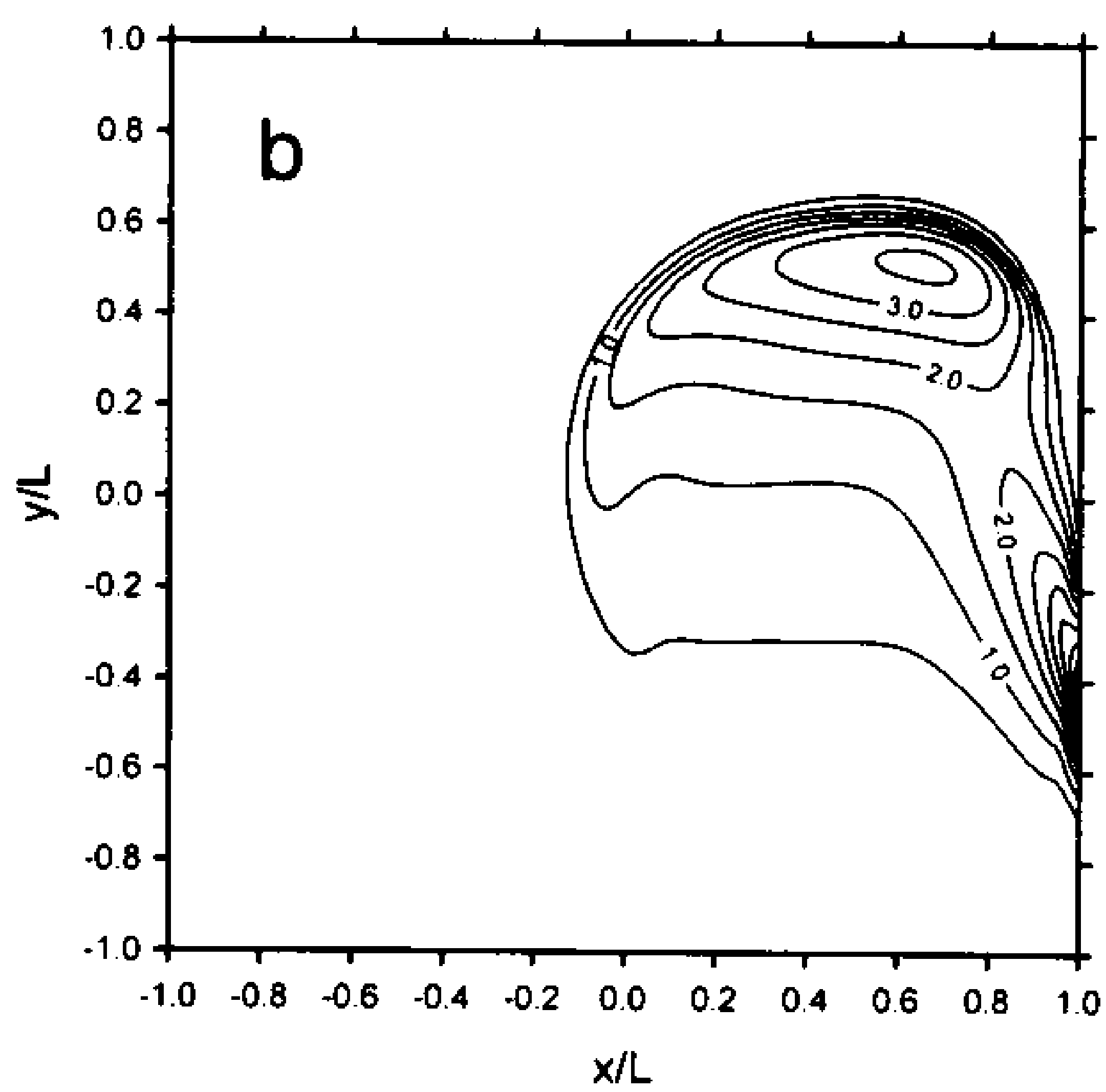

FIG. 6. Evolution of a 3D plume on a sloping bottom with nondimensional slope $\nabla^{\prime} b^{\prime}=10\left(4 \times 10^{-3}\right)$, nondimensional geopotential gradient $\nabla^{\prime} \phi^{\prime}=50\left(u_{0}=0.04 \mathrm{~m} \mathrm{~s}\right)$, maximum nondimensional layer thickness, $\eta_{m}=5\left(h_{m}=100 \mathrm{~m}\right)$. Contour maps of nondimensional layer thickness $\eta$ are shown at (a) $t^{\prime}=0$ and (b) $t^{\prime}=1.6 \times 10^{-2}(2.3$ days). 
a

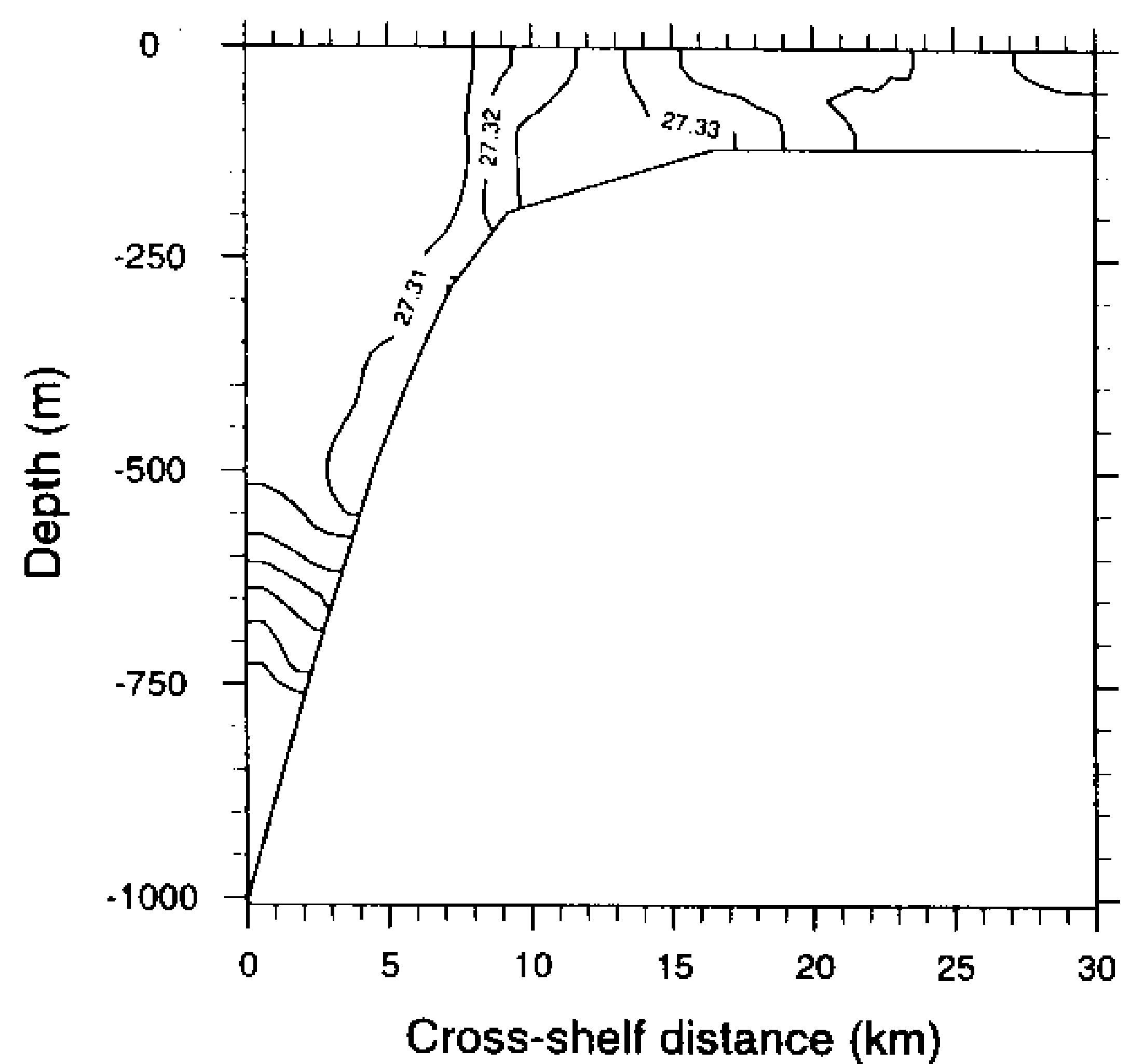

b

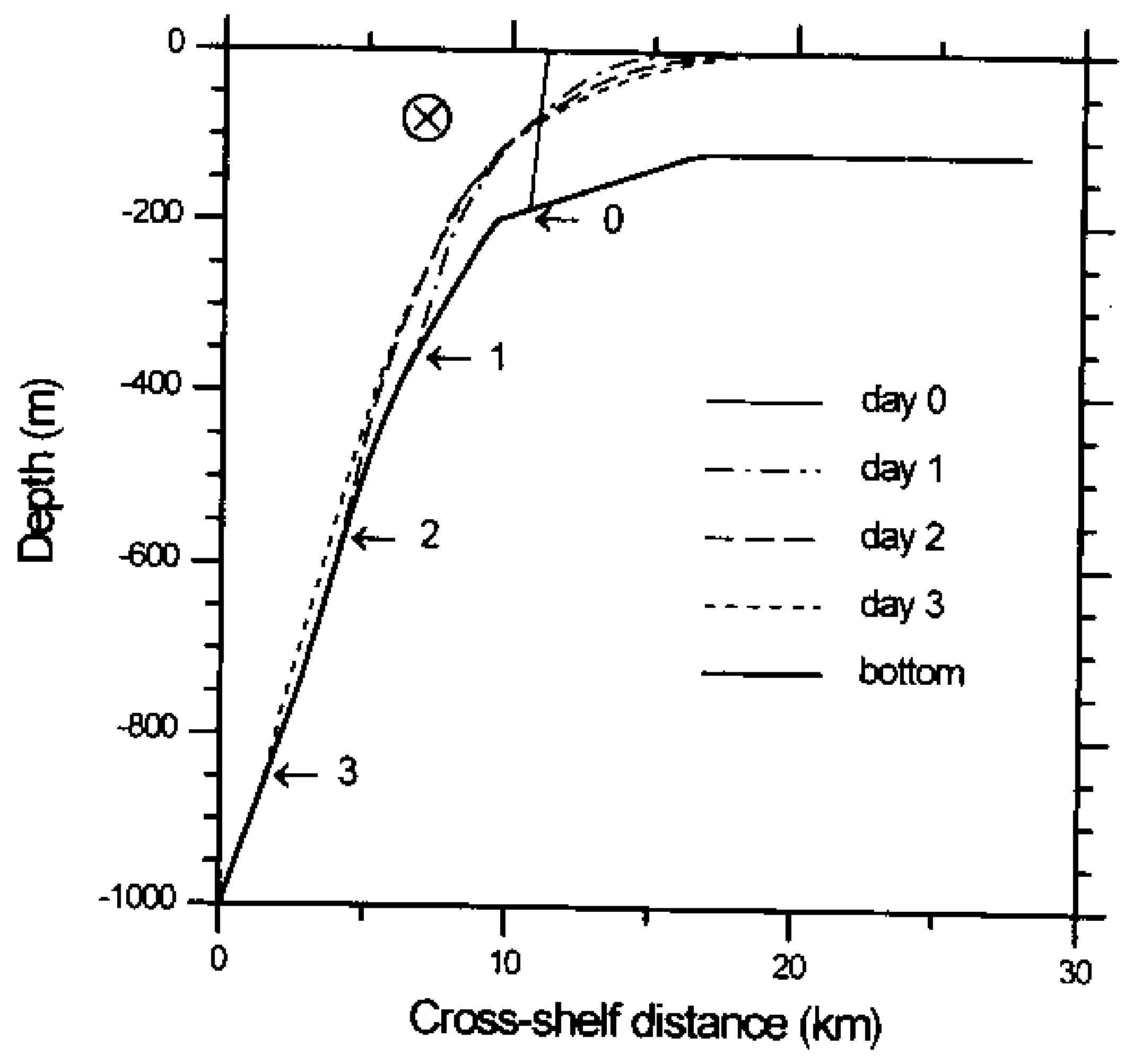

FIG 7. (a) Cross-slope density ( $\sigma$ ) section near $55^{\circ} \mathrm{N}, 10^{\circ} \mathrm{W}$ on the Hebrides slope. (b) Model simulation over real topography. The parameters are $\Delta \rho=0.01 \mathrm{~kg} \mathrm{~m}^{-3}, f=1.2 \times 10^{-4} \mathrm{~s}^{-1}$, and $u_{0}=0.07 \mathrm{~m} \mathrm{~s}^{-1}$. The cross section through the plume is shown at $t=0,1,2$, and 3 days.

no evidence of deep downslope penetration of dense water, although the other sections did show shelf water to be gravitationally unstable with respect to slope water.

An important question in relation to the above observations is how long would it take such a structure to evolve from an initial condition of gravitationally unstable shelf waters? The numerical model has been applied (in two-dimensional form) over the real shelf edge topography at the site on the Hebridean slope where the observations were made. Based on the observational data, the initial density difference between shelf and ocean at the surface was taken as $0.01 \mathrm{~kg} \mathrm{~m}^{-3}$, and the Ekman layer thickness was taken as $h_{E}=40$ $\mathrm{m}\left(U_{T}=0.8 \mathrm{~m} \mathrm{~s}^{-1}\right)$, and the Coriolis parameter, $f=$ $1.2 \times 10^{-4} \mathrm{~s}^{-1}$. An alongslope current $u_{0}=0.07 \mathrm{~m} \mathrm{~s}^{-1}$ was imposed to represent the influence of the Hebrides slope current at this latitude (Huthnance 1986). However, in view of the uncertainties in its value, no entrainment was included. The model suggests that the dense plume would reach the observed depth in about 2.5 days with an average speed of $0.035 \mathrm{~m} \mathrm{~s}^{-1}$ (Fig. $7 \mathrm{~b})$.

The main properties of the cascade can be inferred from the simple order of magnitude relations (11)-(13). From Fig. $7 \mathrm{~b}, \eta=h / h_{E}=1.5$, which gives $R_{1}=0.43$, $R_{2}=0.22, R_{3}=0.92, R_{4}=0.98$, and $R_{6}=0.5$ (see Fig. 2a). Taking the bottom slope as $\tan \theta=8 \times 10^{-2}$, the Nof speed is $g^{\prime} \tan \theta / f=0.067 \mathrm{~m} \mathrm{~s}^{-1}$. The estimated cascading speed $R_{1} u_{\mathrm{Nof}}=0.029 \mathrm{~m} \mathrm{~s}^{-1}$ and the drainage speed is $R_{2} u_{0}=0.015 \mathrm{~m} \mathrm{~s}^{-1}$, so the total downslope velocity can be estimated as $0.045 \mathrm{~m} \mathrm{~s}^{-1}$. The alongslope baroclinic speed of propagation is $R_{3} u_{\text {Nof }}=0.061 \mathrm{~m} \mathrm{~s}^{-1}$, while the slope current forced component of bottomlayer motion (drainage) is $R_{4} u_{0}=0.069 \mathrm{~m} \mathrm{~s}^{-1}$. In this case, therefore, the ratio of cascading/drainage is 2 . On the upper slope the bottom gradient is about $4 \times 10^{-2}$, which gives a cascading/drainage ratio of unity. Drainage may, therefore, be relatively more important on the upper slope and could assist the initiation of shelf-edge cascades. As mentioned previously, some care is needed in the use of the estimated velocities taken from (8) because the governing equation is nonlinear and these cannot be interpreted directly as propagation velocities but only as estimates. An improved method of estimation of the downslope cascade speed is by the application of the "shock-wave" analytical formula (21), which through its derivation takes into account the nonlinearity of the dynamics. In the Hebrides case, with the values of $\eta$ and $R_{6}$ above this gives a speed of 0.022 $\mathrm{m} \mathrm{s}^{-1}$. The total downslope speed including drainage is therefore $0.037 \mathrm{~m} \mathrm{~s}^{-1}$, very close to the numerical result. Of course, in order to obtain the most accurate estimate of cascading speed, the full nonlinear model should be run as was done to obtain Fig. $7 \mathrm{~b}$.

\section{Discussion}

The overall dynamics and especially the dynamics of the bottom layer in shelf-slope regions is strongly influenced by ageostrophic effects. A complex interplay of forces affects the evolution of dense water plumes and lenses in the presence of bottom topography and 
friction. The relative importance of these forces depends on the local plume parameters so that, in general, a dense plume can be expected to distort in a complex manner over time. We have presented a 11/2-layer model that, through analytical and numerical solutions, gives the capacity to simulate the detailed evolution of a bottomlayer plume over realistic bottom topography in the presence of an externally imposed current in the upper layer.

Several authors have considered the motion of dense water masses over sloping bathymetry (e.g., Bowden 1960; Bowers and Lennon 1987) from the point of view of bulk force balances. This approach is underdetermined in terms of unknown variables and cannot be used to make an a priori prediction of plume trajectory. The stream tube approach (Smith 1975) can predict the plume trajectory, but only the cross-sectional area of the plume is determined from the dynamics, and evaluation of plume thickness depends upon specification of how it varies, if known (Price and Baringer 1994). On the other hand, our approach, which comprises force balance as well as mass conservation considerations, can predict both the plume trajectory and its thickness and is not limited to stationary conditions as are the other two approaches.

The governing equation for our model (8) is of the advection-diffusion type and is structured in such a way that inspection of terms allows an estimate to be made of their relative importance. The nonlinearity of the governing equation means that plume velocities are only properly determined by the full solution of the equation. However, some progress can be made by taking the above velocities as broad estimates of plume propagation rates. On account of the balance between pressure gradient, friction, and Coriolis force the density difference between the bottom and upper layers brings about density-driven components of advection both alongslope (with the shallow water to the right in the Northern Hemisphere) and downslope. For the same reason an externally imposed current will advect the bottom layer with vector components in the direction of the main current and perpendicular to it (to the left in the Northern Hemisphere). All of these four vector components are determined by two primary scale velocities modulated by scalar coefficients. These two-scale velocities are the Nof velocity, $g^{\prime} \tan \theta / f$, which represents the speed of alongisobath propagation of long topographic linear waves, and the geostrophic velocity of the external current $u_{0}$. The scalar coefficients are functions of the ratio of the layer thickness to the Ekman depth and are given by (10) and depicted in Fig. 2a. It is interesting that the Nof speed, which originally arises as the key scale for alongslope density-driven motions, also controls the crossslope density-driven motion brought about by Ekman veering.

We distinguish between the two processes that bring about downslope motion in the bottom layer over sloping topography. The first, which we call forced Ekman drainage, is the motion induced by the Ekman veering of an imposed upper-layer alongslope current (e.g., a barotropic eastern boundary current). The second, which we term cascading, is the density-driven downslope component of flow that arises when friction allows part of the downslope reduced-gravity force to drive downslope motion (unbalanced by rotation). For plumes that are thick compared to the Ekman depth, the water transports within the Ekman layer are a small fraction of the total transport within the lower layer. Bottom friction effects are, therefore, relatively unimportant to the overall motion of the plume. For this reason, externally imposed currents drive thick plumes in the direction of flow and, on sloping topography, densitydriven plume translation is principally alongslope. Nevertheless, the model predicts a leakage of dense water away from the plume in the bottom Ekman layer. For thin plumes, friction is of much greater importance and the overall motion is more ageostrophic with relatively larger components of plume advection perpendicular to upper-layer-driven currents (greater drainage) and stronger downslope density-driven motion (cascading).

The theory provides several qualitative insights into shelf-edge cascading. A two-dimensional downslope propagating density-driven plume (no forced drainage) forms a shock-wave structure with a sharp leading edge and a tail of constant thickness. This structure exists in a quasi-stationary state only if the thickness of the main body of the plume is less than about two Ekman depths. If the plume is initially thicker than this, only a nose two Ekman depths thick propagates down slope. The propagation velocity of these fully developed plumes/ noses is about 0.2 times the Nof speed [Eq. (22)]. For these plumes it is also found that the ratio of cascading/ drainage is about two times the ratio of the Nof speed to the (barotropic) externally forced alongslope current.

On the shelf where the bottom slope is small, the density-driven or Nof speed is necessarily small also. The slow propagation speed of a dense plume in the flat-bottomed case (Fig. 3a) highlights the weakness of densitydriven flow in these circumstances. When the bottom slope is small, drainage is likely to prevail over cascading as a downslope forcing mechanism. On the ocean eastern boundaries, where poleward undercurrents or slopetrapped currents meander onto the shelf, their effect will be to force offshelf drainage flows. Consequently this may take dense shelf water close to the steep slope beyond the shelf break where cascading will take over as the primary downslope driving mechanism. Meandering of an alongslope current is thus a possible mechanism to trigger the cascading process. On the other hand, an alongslope current that flows opposite to the direction of topographic wave propagation may resist or even block the descent of dense shelf water, as illustrated in Fig. 4d.

The role of entrainment in downslope cascading is of interest. Without entrainment, the downslope propagation of the leading edge of the plume is severely inhibited by friction, which restricts the supply of water from the main body of the plume to the leading edge necessary to steepen 
the interface and allow density-driven propagation. By thickening the leading edge, entrainment allows more water to reach the leading edge from the plume behind and so increases the speed of propagation (Figs. $3 b$ and $4 b$ ).

Several aspects of the theory warrant further attention in future, such as the role of Ekman pumping by the upper-layer vorticity [first term on the right-hand side of (8)] and the extent to which the theory can be applied to upwelling systems where motion is upslope rather than downslope. The model has been applied largely under two-dimensional conditions in order to extract the important physical insights. Figure 6 , however, demonstrates some of the complexity that can develop under fully three-dimensional conditions. It also shows that the model is capable of describing double frontal currents where the plume thickness vanishes on both upslope and downslope sides, such as in the case of the Mediterranean outflow. It remains to be seen how applicable the simple results derived in two dimensions are in the three-dimensional case. This is particularly relevant since dense cascades in the natural environment are likely to be intermittent in both space and time and thus evolve as three-dimensional features. Nevertheless, the expectation is that some of the insights and results outlined here will be of value and help in the design of future observational programs directed at these important oceanographic phenomena.

Acknowledgments. This research was supported by grant awards from the United Kingdom Natural Environment Research Council (GR9/01895), the Russian Foundation of Basic Research (97-05-65635), the Russian Ministry of Science and Technology through project 0813-01, and the 1996 Sir Kirby Laing Fellowship of the School of Ocean Sciences, University of Wales, Bangor. We are grateful to Dr. A. J. Souza for providing us with Fig. 7a. This work was undertaken during the visit of GIS to the University of Wales, Bangor.

\section{REFERENCES}

Armi, L,, and E. D'Asaro, 1980: Flow structures of the benthic ocean. J. Geophys. Res., 85 (C1), 469-484.

Barenblatt, G. I., 1978: Similarity, Self-Similarity, and Intermediate Asymptotics (in Russian). Gidrometeoizdat, $252 \mathrm{pp}$.

Bowden, K. F, 1960: The dynamics of flow on a submarine ridge. Tellus, 12, 1418-1426.

Bowers, D. G., and G. W. Lennon, 1987: Observations of stratified flow over a bottom gradient in a shallow sea. Contin. Shelf Res., 7, 1105
1121 .

Cooper, L. H. N., and D. Vaux, 1949: Cascading over the continental slope of water from the Celtic Sea. J. Mar. Biol. Assoc. UK, 28 ,
719-750. Csanady, G. T., 1976: Mean circulation in shallow seas. J. Geophys. Res.,
81, 5389-5399.

- 1984: The influence of wind stress and river runoff on a shelf-sea front. J. Phys. Oceanogr., 14, 1383-1392.

Dickson, R. R., E. M. Gmitrowics, and A. J. Watson, 1990: Deep water renewal in northern North Atlantic. Nature, 344, 848-850.

Ezer, T., and G. L. Weatherly, 1990: A numerical study of the interaction between a deep cold jet and the bottom boundary layer of the ocean. J. Phys. Oceanogr., 20, 801-816.

Garrett, C. J. R., and J. W. Loder, 1981: Dynamical aspects of shallow sea fronts. Philos. Trans. Roy. Soc. London, A302, 563-581.

Gill, A. E., 1973: Circulation and bottom water production in the Weddel Sea. Deep-Sea Res., 20, 111-140.

Godunov, S. K., and V. S. Riabenkiy, 1973: Finite Difference Schemes (in Russian). Nauka, 400 pp.

$\mathrm{Hu}, \mathrm{D}$., and H. Bai, 1995: On the transportation and deposition of fine material in the coastal seas surrounding China. Proc. Int. Symp. on Material Flux in Coastal Seas, Qingdao, China, Institute of Oceanology, Chinese Academy of Sciences, p.14.

Huthnance, J. M., 1986: The Rockall slope current and shelf edge processes. Proc. Roy. Soc. Edinburgh, 88B, 83-101.

, 1995: Circulation, exchange and water masses at the ocean margin: The role of physical processes at the shelf edge. Progress in Oceanography, Vol. 35, Pergamon Press, 353-431.

Jungclaus, J. H., and J. O. Backhaus, 1994: Application of a transient reduced gravity plume model to the Denmark Strait overflow. $J$. Geophys. Res., 99 (C6), 12375-12396.

Killworth, P. D., 1977: Mixing on the Weddel Sea continental slope. Deep-Sea Res., 24, 427-448.

Latif, M. A., E. Ozsoy, T. Oguz, and U. Unluata, 1991: Observations of the Mediterranean outflow into the Black Sea. Deep-Sea Res., 38 (Suppl.2), s711-s723.

Lennon, G. W., D. G. Bowers, R. A. Nunes, B. D. Scott, M. Ali, J. Boyle, C. Wenju, M. Herzfeld, G. Johansson, S. Nield, P. Petrusevics, P. Stephenson, A. A. Suskin, and S. E. A. Wijffels, 1987: Gravity currents and the release of salt water from an inverse estuary.
Nature, 327, 696-697.

Lundberg, P. A., 1983: On the mechanics of deep water flow in the Bornholm Channel. Tellus, 35, 149-158.

Melling, H., and E. L. Lewis, 1982: Shelf drainage flows in the Beaufort Sea and the effect on the Arctic Ocean pycnocline. Deep-Sea Res.,
29, 967-985.

Nansen, F., 1913: The waters of the northeastern North Atlantic. Int. Rev. Gesamten Hydrobiol. Hydrogr., Bd 4 (Suppl.), 1-139. Nof, D., 1983: The translation of isolated cold eddies along a sloping
bottom. Deep-Sea Res., 30, 171-182.

Price, J. F., and M. O. Baringer, 1994: Outflows and deep water production in marginal seas. Progress in Oceanography, Vol. 33, Pergamon
Press, 161-200.

- M. O'Neil Baringer, R. G. Luek, G. C. Johnson, I. Ambar, A. Cantos, M. A. Kennely, and T. B. Sanford, 1993: Mediterranean outflow mixing and dynamics. Science, 259, 1277-1282.

Rhines, P., 1989: Deep planetary circulation and topography: Simple models of midocean flow. J. Phys. Oceanogr., 19, 1449-1470. Shapiro, G. I., 1982: On the dynamics of a non-stationary atmospheric
front (in Russian). Meteor. Gidrol., 1, 16-23.

- 1987: Toward a theory of quasigeostrophic motions of finite amplitidein a viscous stratified ocean. Oceanology, 27, 10-15.

- and A. G. Zatsepin, 1996: Gravity current down a steeply inclined bottom in a rotating fluid. Ann. Geophys., 15, 366-374.

Simpson, J. E., 1982: Gravity currents in the laboratory, atmosphere and ocean. Annu. Rev. Fluid Mech., 14, 213-234.

Smith, P. C., 1975: A streamtube model for bottom boundary currents in the ocean. Deep-Sea Res., 22, 853-873.

Speer, K., E. Tzipperman, and Y. Feliks, 1993: Topography and grounding in a simple layer model. J. Geophys. Res. 98(C5), 8547-8558. Tomczak, M., 1985: The Bass Strait cascade during winter 1981. Contin.
Shelf Res., 4, 225-278.

Whitehead, J. A., 1987: Dense water off continents. Nature, 327, 656.

Zejdovich, Y. B., and A. S. Kompaneets, 1950: The theory of heat propagation in the case where conductivity depends on temperature (in Russian). Sbomik Posviaschenny 70-letiyu A.F. Ioffe, Publishing
House of the USSR Academy of Sciences, 61-71.

Zhmur, V. V., and D. V. Nazarenko, 1994: Dynamics of dense fluid in an ocean boundary layer near a sloping bottom (in Russian). Oceanologiya, 34, 193-200.

Zoccolotti, L., and E. Salusti, 1987: Observations of a vein of very dense marine water in the southern Adriatic Sea. Contin. Shelf Res., 7, 